\title{
The expanding role of extracellular traps in inflammation and autoimmunity: The new players in casting dark webs
}

\author{
Stephanie U-Shane Huang ', Kim Maree O'Sullivan',** \\ 1 Centre for Inflammatory Diseases, Monash University Department of Medicine, School of Clinical Sci- \\ ences 246 Clayton Rd, Clayton, VIC 3168, Australia ; stephanie.huang@monash.edu \\ 2 Centre for Inflammatory Diseases, Monash University Department of Medicine, School of Clinical Sci- \\ ences 246 Clayton Rd, Clayton, VIC 3168, Australia : kim.osullivan@monash.edu \\ * Correspondence: kim.osullivan@monash.edu; Tel.: +61 385722090
}

\begin{abstract}
The first description of a new form of neutrophil cell death distinct from that of apoptosis or necrosis was discovered in 2004 and coined neutrophil extracellular traps "(NETs)" or "NETosis". Different stimuli for NET formation, and pathways that drive neutrophils to commit to NETosis have been elucidated in the years that followed. Critical enzymes required for NET formation have been discovered, and targeted therapeutically. NET formation is no longer restricted to neutrophils but has been discovered in other innate cells: Macrophages/Monocytes, Mast Cells, Basophils, Dendritic cells, and extracellular DNA is extruded from both B and T cells. It has become clear that although this mechanism is thought to enhance host defence by ensnaring bacteria within large webs of DNA to increase bactericidal killing capacity, it is also injurious to innocent bystander tissue. Proteases and enzymes released from extracellular traps (ET)s, injure epithelial and endothelial cells perpetuating inflammation. In the context of autoimmunity ETs release over 70 well known autoantigens. ETs are associated with pathology in multiple diseases: lung diseases, vasculitis, autoimmune kidney diseases, atherosclerosis, rheumatoid arthritis and psoriasis. Defining these pathways that drive ET release will provide insight into mechanisms of pathological insult, and provide potential therapeutic targets.
\end{abstract}

Keywords: Extracellular Traps ; Inflammation; Neutrophils; Basophils; Macrophage/Monocytes; Therapeutic Targets; autoimmunity

\section{A brief history of the discovery of NETs}

The widely accepted inaugural accepted characterisation of neutrophil extracellular traps (NETs) is by Brinkman and colleagues in 2004. However, the first description of DNA extrusion by leukocytes dates back to 1975 by Anker et al., who showed spontaneous DNA release in vitro by viable human blood lymphocytes (1). The authors demonstrated that these cells were capable of repeatedly releasing DNA while maintaining the ability to synthesise novel DNA without a decline in viability. Following this discovery, Rogers showed that the extruded DNA is partly composed of the newly synthesised DNA (2), and the original group found that this DNA carries the sequence to generate RNA coded for transcribing antibodies to the stimulating antigen, while spontaneously released DNA did not (3). This suggests that these lymphocytes were capable of producing stimulant-specific DNA instantaneously to eliminate the foreign threat, providing another mechanism of innate immune defence. These were the first descriptions of a process later to be termed vital NETosis, which will be discussed in detail further on in this review.

This was followed by the characterisation of suicidal NETosis by Takei et al. in 1996, whose team was studying the events between neutrophil activation and subsequent death using phorbol 12-myristate 13-acetate (PMA)(4), a robust activator of 
neutrophils. They observed that PMA treated neutrophils exhibited morphological changes that were atypical of apoptosis or necrosis. They used electron microscopy to successfully describe the sequence of events involved in NET formation, starting with fusion of the lobular nucleus, followed by chromatin decondensation and nuclear envelope rupture (4). Of interest he authors found that the cytoplasmic organelles had not begun degradation and membrane permeability started increasing at 3 hours following PMA treatment. They also correctly hypothesised that cell death resulted from oxygen radicals as the use of antioxidants prevented PMA cytotoxicity (4).

The term neutrophil extracellular traps (NETs) was coined three decades after the first description by Brinkman and colleagues (5). Using electron and confocal microscopy, the authors were able to visualise the extrusion of fibrous structures containing DNA fibres from activated neutrophils, coated with proteins from the primary granules (neutrophil elastase, cathepsin $\mathrm{G}$ and myeloperoxidase), secondary granules (lactoferrin), tertiary granules (gelatinase or MMP9), and histones (H1, $\mathrm{H} 2 \mathrm{~A}, \mathrm{H} 2 \mathrm{~B}, \mathrm{H} 3, \mathrm{H} 4$, and the H2A-H2B DNA complex). The NETs were demonstrated to sequester and kill bacteria with the local delivery of antimicrobial molecules (5), the authors concluded that the sequestration of toxic granule proteins such as proteases in the fibrous structure may prevent damage to surrounding tissues. However, they also noted the release of histones may trigger the development of autoimmune conditions (5). Since the discovery of NETs in 2004, other immune cell populations have also been characterised to release DNA structures upon stimulation. These include B cells (6, 7), T cells (7-9), mast cells, eosinophils (10), macrophages/monocytes $(11,12)$, basophils $(13)$ and dendritic cells (DCs). The mechanism of DNA extrusion by these cells will be discussed later on in this review. As a variety of immune cells are capable of producing extracellular DNA traps, the mechanism will be termed ETosis to include all cell types.

While the mechanism of ETosis has been extensively studied in humans and mice since their discovery, it is a highly conserved process. ET formation has been characterised across many species, including bovine (14-20) porcine (21-23), equine (24-26), avian $(27,28)$, and fish (29-34), with more recent publications adding invertebrates (35-39) and plants $(40,41)$ to the repertoire. The common purpose of ETosis in these species is overwhelmingly in defence against pathogenic infection, perhaps a strategy that emerged early on in eukaryotic evolution. Using a congruency test, RamosMartinez et al. found that the ETs across these species exhibited convergent evolution, and the transition from being unicellular to multicellular organisms was crucial for their emergence (42).

As infection and immunity have been two driving forces of evolution for both host and pathogen, certain strains of bacteria have developed surface nucleases to enable their extrication from ETs (43-45). For the host, circulating neutrophils are the first immune cells to be recruited to the site of infection to act as a physical barrier via the extrusion of NETs to contain the foreign pathogen, furthermore, they also play a role in wound healing. Tonello et al. showed that NETs enhanced keratinocyte proliferation in a concentration dependent manner via a NFKB mechanism, suggesting a connection between the initial immune response and induction of wound closure (46). NETs have also been demonstrated to induce wound healing via activation of fibroblasts in myocardial infarction patients (47), and an in vitro study found that dermal fibroblasts co-cultured with NETs upregulated $\alpha$-smooth muscle actin expression and collagen production (48). Whilst NETs can activate wound repair, they have also been shown to impair keratinocyte migration, resulting in delayed wound healing in diabetic patients and mouse models (49-51). Another study showed that interaction between NETs and keratinocytes promoted Staphylococcus aureus 
colonisation in the skin (52). As with any immune process, appropriate activation is sufficient to return the host to homeostasis, whereas dysregulation and persistence of the inflammatory process can have detrimental outcomes. This review will focus on the mechanisms and purpose of ETosis, discuss its role in disease pathogenesis, and potential as a therapeutic target

\section{Pathways to NETosis}

NETosis is differentiated from other cell death processes such as apoptosis and necrosis by the presence of citrullinated histones, where arginine is converted to citrulline by peptidyl arginine deiminase (PAD4)(53). The role of PAD4 in this process was further established using a pan-PAD inhibitor to demonstrate the decrease of histone citrullination, resulting in the failure of NET formation (54). Further work from the same group used KO mouse models to show the abrogation of NET-mediated bacterial killing (55). NETosis has also been characterised to be independent of apoptotic caspases (56-59), further distinguishing it from the apoptotic process. Contradicting studies have found NETosis to be both mixed lineage kinase domain-like pseudokinase (MLKL) and receptor interacting serine/threonine kinase 3 (RIPK3) dependent and independent using different stimuli. PMA (60), crystalline particles (61), activated platelets (62), and anti-neutrophil cytoplasmic antibodies (ANCA) were shown to induce NET formation via RIPK1 and RIPK3 (63). Contrarily, other groups used PMA, lipopolysaccharide (LPS), or complement component C5a (64), C. albicans, nigericin, group B streptococci or the calcium ionophore A23187 (58) to show that the activation of RIPK1 or RIPK3 were not necessary to trigger NET formation. These findings suggest that NETosis may require necroptosis machinery following induction by certain stimuli but not others. A comprehensive summary of each NETosis process is shown in table 1.This active form of cell death is characterised by two distinct phases: 1) early vital NETosis after initial phagocytosis and chemotaxis, followed by 2) late suicidal NETosis, where neutrophils release their DNA and enzymes to trap the pathogen, thus sacrificing themselves to contain the threat. These different forms of NETosis are shown in the schematic in figure 1.

\subsection{Vital NETosis}

Neutrophils can discriminate between different bacteria and activate either vital or suicidal NETosis accordingly (65). A dynamic process of vital NETosis has been characterised during both gram-positive and gram-negative infections, where neutrophils cast large NETs to prevent the dissemination of bacteria while the membrane remains intact $(66,67)$. This early form of vital NETosis can occur independently of reactive oxygen species (ROS) production. Platelets have been characterised to activate NETosis against Staphylococcus aureus infection (68). Confocal and electron microscopy were used to capture the temporal events of vital NETosis in response to Staphylococcus aureus, showing nuclear dilatation occurring at 25 minutes following incubation, followed by nuclear condensation at 45 minutes, subsequent nuclear breakdown occurred at 60 minutes, with the release of DNA material into cytoplasm (67). Vesicles released from nuclear envelope containing DNA strands are released into the extracellular (EC) space, where they lyse and form NETs. Some dense granules were also extruded into the EC space (67). 


\begin{tabular}{|c|c|c|}
\hline Vital & Suicidal & Caspase-dependent \\
\hline $\begin{array}{l}\text { Neutrophil } \\
\text { chemotaxing } \\
\text { toward } \\
\text { bacterium }\end{array}$ & $\begin{array}{l}\text { Priming by EC } \\
\text { or IC stimuli }\end{array}$ & $\begin{array}{l}\text { Detection of } \\
\text { cytosolic LPS }\end{array}$ \\
\hline $\begin{array}{l}\text { Nuclear } \\
\text { delobulation } \\
\text { and release of } \\
\text { DNA containing } \\
\text { vesicles }\end{array}$ & $\begin{array}{l}\text { PKC } \\
\text { activation and } \\
\text { Raf-MEK-ERK } \\
\text { pathway } \\
\text { induction }\end{array}$ & $\begin{array}{l}\text { Caspase- } 11 \\
\text { activation and } \\
\text { GSDMD } \\
\text { cleavage }\end{array}$ \\
\hline $\begin{array}{l}\text { Nuclear } \\
\text { envelope } \\
\text { breakdown } \\
\text { and vesicles } \\
\text { fusing with } \\
\text { plasma } \\
\text { membrane }\end{array}$ & $\begin{array}{l}\text { NE and MPO } \\
\text { migrate to } \\
\text { nucleus, } \\
\text { degrade } \\
\text { chromatin and } \\
\text { nuclear } \\
\text { envelope }\end{array}$ & $\begin{array}{l}\text { GSDMD forms } \\
\text { pore in } \\
\text { nuclear } \\
\text { membrane, } \\
\text { caspase- } 11 \\
\text { enters and } \\
\text { cleaves } \\
\text { histones }\end{array}$ \\
\hline $\begin{array}{l}\text { Release of DNA strands } \\
\text { and NET formation by } \\
\text { anuclear neutrophil }\end{array}$ & $\begin{array}{l}\text { GSDMD-mediated plasma } \\
\text { membrane lysis and DNA } \\
\text { release }\end{array}$ & $\begin{array}{l}\text { GSDMD creates pore in } \\
\text { plasma membrane to allow } \\
\text { DNA extrusion }\end{array}$ \\
\hline
\end{tabular}

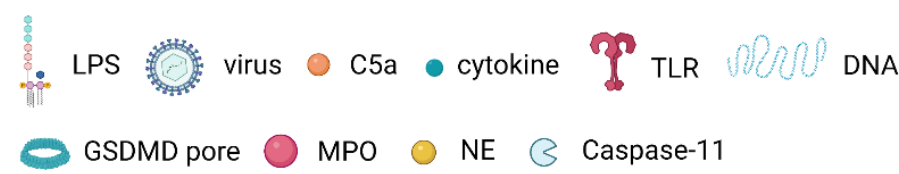

Figure 1. Types of neutrophil extracellular trap (NET) formation. Vital NETosis is initiated by the detection of gram-positive or gram-negative bacteria via toll-like receptor 2 (TLR2)(66, 67), with the neutrophil continuing to migrate toward the bacterium. This is followed by nuclear condensation and release of DNA containing vesicles, which fuse with the outer membrane and release their contents to the extracellular space to form NETs. Nuclear envelope breakdown occurs to form anuclear neutrophils. Priming of suicidal NETosis occurs with the detection of cytokines such as tumour necrosis factor $\alpha$ (TNF $\alpha)$ and interleukin 8 (IL8) $(5,259)$; the complement component, C5a (158); lipopolysaccharide (LPS) (5); and viral glycoproteins (76-78), among other stimulants. This activates protein kinase C (PKC)(79) and the Raf-MEK-ERK pathway (80), while the nucleus begins to lose lobules (56). These series of events are followed by an NADPH-mediated oxidative burst $(56,57)$, which release contents from the granules such as neutrophil elastase (NE) and myeloperoxidase (MPO) into the cytoplasm $(83,84)$. NE and MPO migrate to the nucleus to act synergistically for the cleavage of histones and disintegration of the nuclear membrane (84). NE also cleaves gasdermin D (GSDMD), enabling pore formation in the plasma membrane and NET release (59). Like suicidal NETosis, caspase-dependent NETosis is also dependent on GSDMD for plasma membrane pore formation. It has been found to be triggered by cytosolic LPS 
(88), activating caspase-11, which cleaves GSDMD, leading to pore formation in the nuclear membrane, enabling the translocation of caspase-11 into the nucleus for histone cleavage (88). GSDMD subsequently forms pores in the plasma membrane for NET extrusion (88). Figure created using Biorender.

Yipp and colleagues used time-lapse microscopy to study the morphological changes of neutrophils undergoing vital NETosis, demonstrating the development of diffuse decondensed nuclei that become deficient in DNA, subsequently exhibiting unusual crawling behaviour where the nucleus is used as a fulcrum for crawling (66). The study found that vital NETosis was toll-like receptor 2 (TLR2) and complement 3 (C3) dependent, as both Tlr2-/- and C3-/- mice were unable to release histones or nuclear DNA, and NETosis was restored with normal mouse serum (66). The authors used intravital microscopy and 3D reconstruction techniques to show that the neutrophils undergoing NETosis had intact membranes and remained viable, they also continued to migrate toward bacteria (66). This process was vital in preventing the invasion of bacteria, where disruption of NETs using DNAse resulted in bacteraemia at $4 \mathrm{hrs}(66)$. The authors noted that as multiple bacteria have the capacity to induce DNAse and escape NETs $(43,45,69,70)$, it is crucial for the anuclear neutrophils to maintain killing capacity. Their study found that neutrophils formed NETs while crawling and had the ability to activate phagocytosis at any time (66). The authors also noted the ability of NETs to cause autoimmune disorders and concluded that the viable form of NETosis is tightly regulated, which may limit bystander effect.

Recently, viable neutrophils have also been found to release mitochondrial DNA (mtDNA) NETs in a ROS dependent manner in response to granulocyte-macrophage colony-stimulating factor (GM-CSF) and C5a (71). Recent studies have shown the release of mtDNA NETs by low density neutrophils in lupus nephritis, which were demonstrated to be pro-inflammatory and induced type I interferons (IFNs) via the cyclic GMPAMP synthase and stimulator of interferon genes (cGAS-STING) pathway (72). The administration of a mitochondrial ROS inhibitor was sufficient in reducing NETosis and alleviate autoimmunity in mouse models of lupus (72). Another study showed the induction of mtDNA NET release from neutrophils following orthopaedic trauma surgery (73), which induced further NET formation via TLR9 and nuclear factor kappa B (NFKB) in a nicotinamide adenine dinucleotide phosphate (NADPH) oxidase independent manner $(74,75)$.

\subsection{Suicidal NETosis}

The most extensively characterised form of NETosis is suicidal NET formation, which is longer temporal process compared to vital NETosis and ends in cell death. NETs are produced by activated neutrophils, which can be stimulated by factors such as PMA, LPS, and cytokines such as interleukin 8 (IL-8) (5). Viral infections have also been characterised to induce neutrophil activation via TLR4, 7, or 8 recognition (76-78).

The process of NET formation and release was studied by Fuchs et al. using multichannel live-cell imaging and transmission electron microscopy (56), to characterise the event as an active form of cell death. The NETosis process starts around 60 minutes following PMA stimulation, where the nuclei start to lose lobules; at 80 minutes, the nuclei begin to expand and fill the intracellular space; 120 minutes is when the nuclear 
membrane starts to form vesicles; at 180 minutes, the nuclear envelope disintegrates into small vesicles and chromatin becomes decondensed; finally, at 220 minutes, the cells lose membrane integrity and start to rupture (56). Several other groups have used PMA as a stimulus to characterise each of the steps in NETosis, showing the sequence of biochemical events to start with protein kinase C (PKC) activation (79); followed by Raf-MEK-ERK pathway induction (80); then NADPH oxidase mediated ROS production $(56,57,81)$; myeloperoxidase (MPO) activation (82) and release of neutrophil proteases including neutrophil elastase (NE) and MPO from granules into the cytoplasm $(83,84)$; subsequent migration of NE to nucleus via a ROS dependent process, and synergistic effect between $\mathrm{NE}$ and MPO drives actin degradation in an enzyme independent process $(83,84)$; finally, nuclear membrane disintegration, chromatin decondensation, plasma membrane lysis and NET release (56). Recently, gasdermin D (GSDMD) was also found to be an essential protease in NET formation (59). Using mutagenesis techniques, Sollberger and colleagues showed that NE released from the primary granules cleaved GSDMD at several amino acid residues similar to those recognised by caspase 4 to activate its poreforming properties (59). A series of inhibition experiments determined that GSDMD acted downstream of the oxidative burst (59).

Suicidal NETosis requires the production of ROS, this was demonstrated using a NADPH oxidase inhibitor, which prevented NET formation (56). This is further supported by clinical evidence from patients with Chronic Granulomatus Disease (CGD), who have mutations in NADPH, rendering them unable to generate ROS and subsequently unable to produce NETs (56). However, NETosis was restored with the addition of glucose oxidase to the patients' neutrophils, stimulating the generation of hydrogen peroxide, a ROS, resulting in the formation of NETs (56).

Recently, Domer and colleagues demonstrated that NETs could induce further NET formation by neutrophils, creating a positive feedback loop, amplifying bacterial killing but also inflammation if not appropriately regulated (85). The authors also showed that NET exposure induced phosphorylation of protein kinase B (PKB or AKT), extracellular signal-regulated protein kinase 1/2 (ERK1/2) and p38; the release of IL-8 and B-cell activating factor (BAFF) by neutrophils at 18 hours, but not the previously reported cytokine, tumour necrosis factor $\alpha$ (TNF $\alpha)$ (86). This auto-amplification loop may lead to excessive release of BAFF, which may result in the generation of autoantibodies (87), leading to autoimmunity.

\subsection{Caspase dependent NETosis}

Cytosolic LPS or gram-negative bacteria have been found to induce a caspase dependent form of NETosis via the activation of caspase 11, where it cleaves GSDMD, leading to pore formation in the nuclear membrane (88). This nuclear pore allows the entry of caspase 11 and the cleavage of histones, leading to the relaxation of chromatin. Subsequently, GSDMD creates a pore in the plasma membrane to enable the extrusion of DNA $(59,88)$. Surprisingly, NE, MPO and PAD4 were not necessary in this form of NETosis, where caspase 11 and GSDMD are the direct inducers (88).

While the different mechanisms of NETosis create a comprehensive repertoire in the prevention of pathogenic invasion, it also has the ability to cause excessive and chronic inflammation, with the potential for the development of autoimmune conditions, a few of 
which will be discussed in this review. An overview of the involvement of NETs in the pathogenesis of each disease is summarised in figure 2.

Figure 2. Neutrophil extracellular traps (NETs) in disease pathology. Acute kidney in-

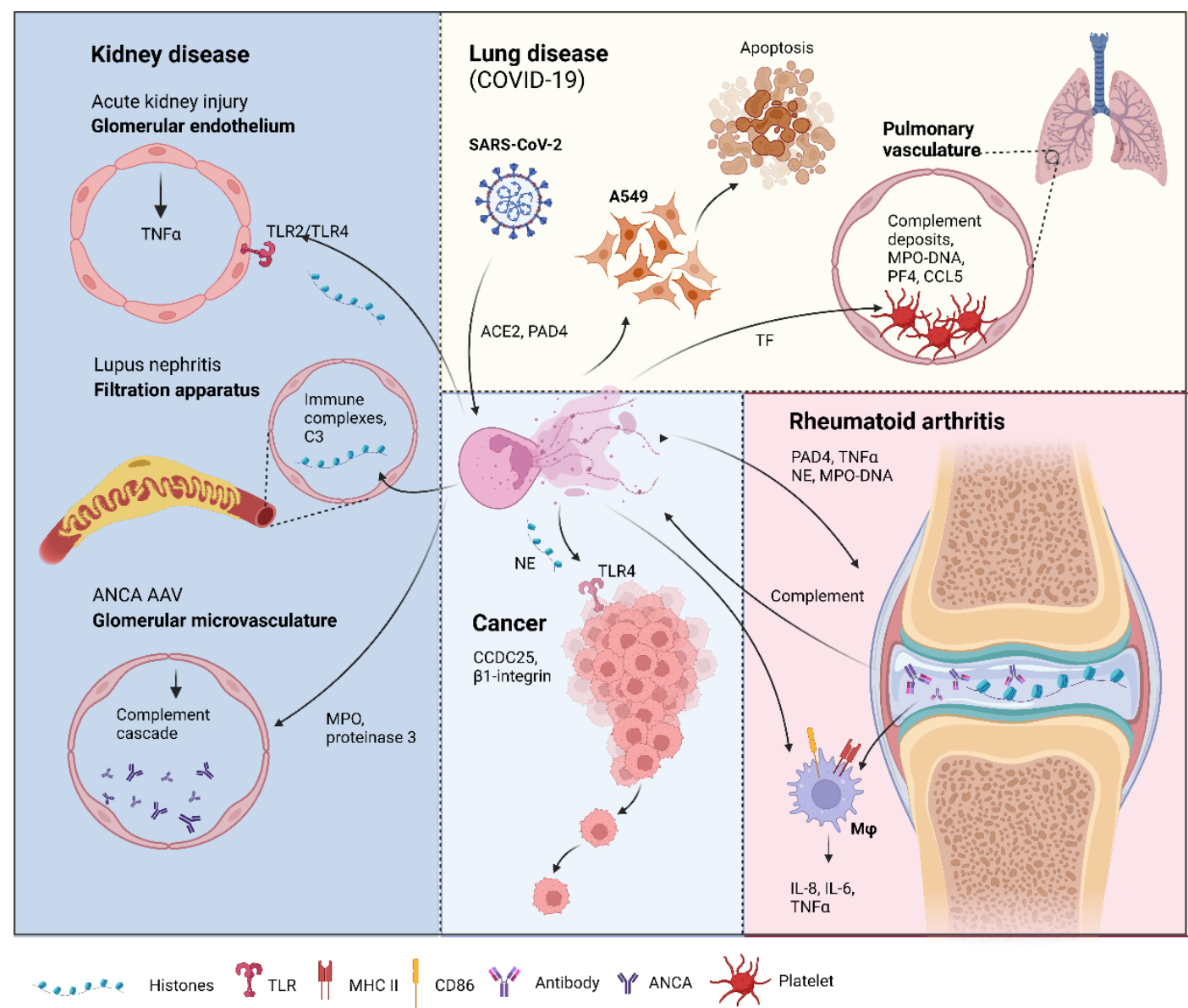

jury: NETosis in the glomerular capillaries results in histone release, triggering renal cell necrosis via toll-like receptor 2 (TLR2)/TLR4, leading to tumour necrosis factor (TNF $\alpha$ ) release (119). Lupus nephritis: Accumulation of immune complex deposits containing anti-double stranded DNA (dsDNA) IgG and its target, plus the complement component, C3, attract neutrophils to the renal filtration apparatus (123). Presence of hyperacetylated histones in the immune deposits trigger an increase in reactive oxygen species independent NETosis (129). Anti-neutrophil cytoplasmic antibodies (ANCA) associated vasculitis (AAV): Neutrophils from AAV patients undergo spontaneous NETosis (140). ANCA against myeloperoxidase and proteinase 3, two proteins in neutrophil granules are found in the glomerular microvasculature 135 (134). These autoantigens activate the complement cascade and induce further NETosis $(135,136)$. Lung disease in coronavirus disease19 (COVID-19): Severe acute respiratory syndrome-related coronavirus 2 (SARS-CoV-2) can induce NETs via an angiotensin converting enzyme 2 (ACE2) and PAD4 dependent mechanism (172). These NETs can enhance the apoptosis of a human alveolar basal epithelial cell line, A549 (72). Complement deposits in the pulmonary vasculature prime neutrophils for NETosis, resulting in myeloperoxidase (MPO)-DNA complexes. Elevation of platelet factor 4 (PF4), chemokine ligand 5 (CCL5) (176), and the neutrophil-platelet interaction all trigger NETosis $(178,179)$, which was shown to have thrombogenic activity via the upregulation of tissue factor (TF)(178). Rheumatoid arthritis (RA): Peptidylarginine deiminase 4 (PAD4) citrullinates histones released by spontaneous NETosis, forming immune complexes in the synovial joint that activate macrophages $(m \varphi)(161)$. The immune complexes can also activate the complement cascade, which triggers, further NETosis (162). NETs from RA donors can activate resting macrophages to induce the surface expression of major histocompatibility complex II (MHCII) and cluster of differentiation 86 (CD86)(86). These macrophages also release interleukin-6 (IL-6), IL-8, and TNF $\alpha$ (86), 
which can feedback to induce more NET formation. Cancer: Cancer cells attract neutrophils into the cancer microenvironment (CME), which results in NET formation under the inflammatory CME. These NETs can capture circulating tumour cells via $\beta 1$-integrin (95), citrullinated histones from NETs can also enhance cancer metastasis by binding to coiled-coil domain containing protein 25 (CCDC25)(97). NETs and the neutrophil elastase (NE) released can promote tumour cell growth via TLR4 (99).

\section{NETs - friend or foe in human disease?}

\subsection{Cancer}

Cancer cells attract neutrophils (tumour-associated neutrophils, TANs), which result in the release of NETs into the tumour microenvironment. NETs have been found in several types of mammalian tumours, including pancreatic, breast, liver, lung and gastric cancers; their presence in solid tumours is associated with poorer prognosis (89-91). While NETs can exert anti-tumour actions via MPO $(92)$, proteinases $(89,93)$ and histones $(94)$, the proteinases can also digest the extracellular matrix (ECM), enhancing metastasis $(89,93)$. Additionally, it has been shown that NETs are capable of capturing circulating tumour cells via the upregulation of $\beta 1$-integrin expression, an interaction that was abrogated using DNase (95). It is therefore, unsurprising that NETs have been found around metastatic tumours (96). In fact, citrullinated histones from NETs were found to promote cancer metastasis by binding to coiled-coil domain containing protein 25 (CCDC25) (97). CCDC25 knockout cells were found to lose their adhesive properties to NET-DNA; NET-DNA induced cytoskeleton remodelling was inhibited; and chemotaxis toward NET-DNA was reduced (97). Injection of the CCDC25 KO cells into immunocompromised mice significantly inhibited NET-mediated lung metastases. Contrarily, overexpression of CCDC25 enhanced cancer cell adhesion and migration toward NET-DNA in vitro, and promoted formation of lung and liver metastases in vivo (97). Additionally, the authors found high CCDC25 expression in primary tumours to be associated with poor prognosis (97). Another group showed the ability of NETs to promote gastric cancer metastasis via the induction of epithelial-mesenchymal transition (EMT), enabling intravasation of tumour cells into the circulation or lymphatics, leading to tumour formation at a distant tissue site (Pastushenko, 2019). Using western blot and immunohistochemical analysis, the authors showed decreased levels of E-cadherin, an epithelial adhesion marker, and increased levels of vimentin, a mesenchymal marker in human gastric adenocarcinoma cells treated with NETs (98).

In addition to the pro-metastatic function of NETs, they have also been shown to promote tumour cell growth by enhancing their mitochondrial functions (99). Yazdani et al. showed that stressed cancer cells upregulate the expression of several chemokines and high mobility group box 1 (HMGB1), recruiting neutrophils to the tumour microenvironment (TME), inducing NET formation. NETs and the NE present in the fibrous structure were demonstrated to promote mitochondrial homeostasis, increasing energy production, and accelerating cancer cell proliferation via TLR4. The blockade of this interaction through genetic manipulation, pharmaceutical inhibition or siRNA targeting of the axis 


\begin{tabular}{|c|c|c|c|c|}
\hline Type of NETosis & Vital & Mitochondrial & Suicidal & Caspase dependent \\
\hline Stimuli & $\operatorname{LPS}(66,67)$ & $\begin{array}{l}\text { GM-CSF (71), C5a (71), } \\
\text { RNP ICs (72) }\end{array}$ & $\begin{array}{l}\text { PMA }(4,5,60), \text { LPS (5), vi- } \\
\text { ral glycoproteins (76-78), } \\
\text { C. albicans (258), C5a } \\
(158), \text { IL-8 (5), crystalline } \\
\text { particles (61), activated } \\
\text { platelets (62), ANCA (63), } \\
\text { TNF } \alpha(259)\end{array}$ & Cytosolic LPS (88) \\
\hline Receptors & TLR2 (66) & TLR7 (260) & $\begin{array}{l}\text { TLR4 (77), TLR7 (76, 78), } \\
\text { TLR8 }(76,78), \text { C5aR1 } \\
(158), \text { TNF } \alpha \text { R }\end{array}$ & \\
\hline Adaptors & C3 (66) & & $\begin{array}{l}\text { PKC (79) GSDMD (59), } \\
\text { MLKL/RIPK3 (stimulus } \\
\text { dependent)(60-63) }\end{array}$ & Caspase-11, GSDMD (88) \\
\hline Cascades & & & $\begin{array}{l}\text { Raf-MEK-ERK (80), ERK } \\
\text { and p38 MAPK (77), AKT } \\
\text { (85) }\end{array}$ & \\
\hline Oxidant reliance & ROS independent (67) & ROS dependent $(71,72)$ & $\begin{array}{l}\text { ROS production }(56,57, \\
77,81)\end{array}$ & \\
\hline $\begin{array}{l}\text { Components re- } \\
\text { leased }\end{array}$ & $\begin{array}{l}\text { DNA, histones and dense } \\
\text { granules }(66,67)\end{array}$ & Mitochondrial DNA & $\begin{array}{l}\text { DNA, histones and pro- } \\
\text { teins from primary }(5,84, \\
261,262) \text {, secondary and } \\
\text { tertiary granules (5) }\end{array}$ & DNA and histones (88) \\
\hline $\begin{array}{l}\text { Downstream path- } \\
\text { ways activated }\end{array}$ & & $\begin{array}{l}\text { TLR9 (74), NFкB (75), } \\
\text { cGAS-STING, Type I IFN } \\
\text { (72); }\end{array}$ & $\begin{array}{l}\text { Complement cascade (63), } \\
\text { IL-17 }\end{array}$ & \\
\hline
\end{tabular}

\section{Table 1. Comparisons of NETosis mechanisms}

AKT: protein kinase B; ANCA: anti-neutrophil cytoplasmic antibody; cGAS-STING: cyclic GMP-AMP synthase and stimulator of interferon genes; EC: extracellular; DNA: deoxyribonucleic acid; ERK: extracellular signal-regulated protein kinase; GMCSF: granulocyte-macrophage colony-stimulating factor; GSDMD: gasdermin D; IFN: interferon; IL: interleukin; LPS: 
lipopolysaccharide; MAPK: mitogen activated protein kinase; MEK: ERK kinase; MLKL: mixed lineage kinase domain-like; NET: neutrophil extracellular trap; NFKB: nuclear factor kappa B; PKC: protein kinase C; PMA: phorbol 12-myristate 13-acetate; Raf: rapidly accelerated fibrosarcoma proto-oncogene serine/threonine-protein kinase; RIPK3: receptor interacting serine/threonine kinase 3; RNP IC: ribonucleoprotein immune complex; ROS: reactive oxygen species; TLR: toll-like receptor; TNF $\alpha$ : tumour necrosis factor $\alpha$

components were shown to abrogate mitochondrial biogenesis and impede tumour growth (99).

\subsection{Multiple sclerosis}

Myelin damage in the white matter may result from the failure to maintain compact myelin, resulting from abnormally enhanced citrullination of myelin basic protein (MBP), which form less cationic isomers, thereby destabilising the myelin multilayers (100). This also enhances the susceptibility of the myelin sheath to digestion by proteases (101). Additionally, citrullinated MBP causes fragmentation of lipid vesicles of the myelin layer, which may contribute to further demyelination $(102,103)$. Furthermore, studies have found the degree of MBP citrullination to correlate with disease severity $(104,105)$. Unsurprisingly, increased levels and enzyme activity of PAD4 have been found in the central nervous system (CNS) of multiple sclerosis (MS) patients and animal models, with an associated increase in citrullinated histone observed in the white matter $(54,106)$. Nuclear PAD4 and TNF $\alpha$ were shown to be elevated before the onset of the demyelinating disease in mouse models [81], suggesting their value as prognostic markers for MS. Furthermore, an elevated level of TNF $\alpha$ was detected to be released by astrocytes and not infiltrating immune cells (106), which may contribute further to local inflammation by priming neutrophils for NET formation.

Current clinical evidence that neutrophils may contribute to MS pathogenesis demonstrate their elevated abundance in MS patients, in an activated state with reduced apoptosis. These neutrophils also have increased levels of TLR2, IL8R, enhanced degranulation and oxidative burst (107). Elevated levels of NETs have been detected in the serum of MS patients (107), with NE levels directly correlating with disease severity and clinical prognosis (108), while significantly more MPO-DNA were complexes detected in male patients, who tend to have poorer prognosis than their female counterparts $(107,109)$. Pharmaceutical intervention may also play a role in disease progression, where patients on corticosteroid treatment were found to have significantly increased NE activity, whereas patients on IFN $\beta-1 b$ treatment showed a lower level of NE and immune complexes (110).

The most recent elucidation of the mechanistic role of NETs in MS pathogenesis was performed by Wilson et al., showing that histones can directly activate T cells for T-helper 17 (Th17) differentiation via TLR2 and myeloid differentiation primary response 88 (MyD88), leading to the phosphorylation of signal transducer and activator of transcription (STAT3) [89], essential for Th17 cell responses [90]. Komiyama et al. also demonstrated the ability of NETs to activate inflammatory Th17 cells, which can secrete IL-17, a neutrophil chemotaxis cytokine [87]. Using IL-17-/- mice, the authors showed a significant decrease in immune cell infiltrate, delayed the onset and reduced disease severity [87], providing a potential therapeutic target for MS treatment. Other groups have demonstrated that pharmaceutical inhibition of MPO reduced oxidative stress and enhanced integrity of the blood brain barrier (BBB), decreasing disease severity $(111,112)$. 


\subsection{Kidney Disease}

The kidney is prone to immune responses that lead to the development of renal injury and chronic kidney disease progression (113-116). This can trigger neutrophil infiltration to the site of injury, compounded by the damage-associated molecular patterns (DAMPs) released by the necrotic renal cells, inflammation and tissue damage become amplified in the kidney (114, 117). The released DAMPs then go on to stimulate the infiltrating neutrophils and induce PAD4 activation, which triggers chromatin decondensation and NET formation (118).

\subsubsection{Acute kidney injury (AKI)}

Acute kidney injury can occur as a consequence of necroinflammation, an interplay of injury and inflammation, where complement activation, exotoxins, or cytotoxic T cells can trigger renal cell necrosis (117). Kumar et al. showed that NETosis results in histone release, leading to glomerular endothelial cell death in an TLR2/TLR4 dependent manner (119). EC histones also trigger release of TNF $\alpha$ in the glomerular capillaries (119), a cytokine that is not only an inducer of NET formation (86), but also characterised to be prothrombotic (120-122). This study provided evidence for the presence of fibrinogen within the glomerular capillaries, which was abrogated with an anti-histone IgG (119). Damage by histone release from NETosis was further characterised by Nakazawa et al. to show that histone citrullination is essential in inducing NET formation (118). Additionally, tubular cells killed via NETosis released factors that triggered further NET formation (118), creating an auto-amplification loop for inflammation.

\subsubsection{Lupus nephritis}

NETosis is commonly found in active systemic lupus erythematosus (SLE) (123). One of the most serious complications of SLE is nephritis, inflammation of the renal filtration apparatus, with chronic autoimmune insults to the glomerulus eventually leads to kidney failure (124-126). A key characteristic of lupus nephritis is immune complex deposits containing antidouble stranded DNA (dsDNA) IgG and its target, along with C3 accumulation, both attracting inflammatory cell infiltrates (123). Furthermore, the presence of dsDNA can activate type I IFN signalling via the cGAS-STING pathway (127), enhancing the inflammatory response.

Presence of NETs in renal biopsies from lupus nephritis patients may indicate their contribution to kidney damage (128). Rother et al. revealed that hyperacetylated histones were present in the SLE immune deposits and stimulated an increase in ROS independent NETosis within 30mins (129). They also showed that immune deposits from patients with active lupus nephritis displayed the highest acetylation levels and were the most potent at inducing NETs compared to SLE patients without nephritis (129). Furthermore, SLE patients with nephritis or prior nephritis have an inability to degrade NETs due to impaired DNase activity (129), thus, existing NET deposits can stimulate further inflammation. This impaired NET removal from patient serum correlates with proteinuria, decreased albumin levels, and lower creatinine clearance rates, all indicators of active nephritis $(130,131)$.

\subsubsection{ANCA-Associated vasculitis}


ANCA-associated vasculitis (AAV) comprises part of a group of immune vasculitides, characterised by necrotising inflammation of small vessels and circulating ANCAs (132). The three types of AAV include granulomatosis with polyangiitis, microscopic polyangiitis (MPA), and eosinophilic granulomatosis with polyangiitis (133). The presence of ANCA against myeloperoxidase (MPO) and proteinase 3, two proteins in neutrophil granules, is characteristic of ANCA-associated vasculitis (134). As discussed previously, both autoantigens are present in NETs, and have been characterised to increase cell adhesion, activate the complement cascade, and induce NET production $(135,136)$. MPO can act as autoantibody to induce more circulating ANCAs, promoting subsequent development of MPA (137), an ANCA-associated pathology that affects the small vessels in the renal glomeruli in particular (138). Immunoglobins purified from MPA patients have demonstrated the ability to induce NETs in direct correlation with the affinity of ANCA for MPO (137). DNAse I activity is also lower in MPA patients, indicating insufficient degradation of NETs (139), which has been found to be responsible for the renal damage observed in up to $90 \%$ of MPA patients (140).

Although the current paradigm assumes that ANCAs induce NET formation, Neutrophils from AAV patients are not prone to apoptosis, but can spontaneously undergo NETosis (140). Furthermore, recent data has shown that NETosis in AAV is independent of serum ANCA levels (141). Additionally, excessive NET formation in AAV is directly correlated with active clinical disease rather than severe infection, implicating the significant role of NETs in autoimmunity (141).

\subsubsection{Goodpastures Disease (anti Glomerular basement membrane disease)}

Akin to lupus nephritis and ANCA-AAV, the pathogenesis of anti-glomerular basement membrane (GBM) disease involves both immune complex deposition and microvascular damage (142). These immune complexes stimulate NETosis, triggering Fc $\gamma$ R-mediated endocytosis and tyrosine-protein kinase ABL/proto-oncogene tyrosine-protein kinase Src (Abl/Src) kinase activation, leading to glomerular endothelial injury $(143,144)$, where disease could be attenuated by inhibiting Abl/Src signalling in a bovine model (144). A murine anti-GBM glomerulonephritis model showed the presence of NETs in a necrotising lesion, where histones from NETs were shown to cause capillary injury, which was ameliorated using PAD inhibitors and anti-histone antibodies (119). Contrarily, research by another group found that PAD4 inhibition using either antibody or genetic deletion had no protective effect in anti-GBM disease (145), challenging the role of NETs in anti-GBM pathogenesis.

\subsubsection{Vasculitis}

Vasculitis is a broad term encompassing diseases involving inflammation of the blood vessels (146), it includes ANCA-associated vasculitis (AAV, small-vessel vasculitis), Takayasu arteritis (large-vessel vasculitis), and giant cell arteritis (147). Contention exists around whether NETosis is a hallmark of active AAV as high levels of NET remnants are found in all three types of vasculitis mentioned above (140). However, proteinase 3-ANCA (PR3-ANCA) and MPO-ANCA have been found in most vasculitis patients, both characteristic of AAV pathogenesis (148). Several studies have shown that autoantibodies, serum immune complexes, and IgG derived from patients with AAV have the capacity to induce NETosis (128, 139, 149-152). Recent work has shown that MPO-ANCA may cause NETosis in patients with vasculitis due to 
its affinity rather than the antibody levels $(139,150,153)$. These findings are further supported by a renal biopsy study, where individuals with high affinity MPO-ANCA demonstrated enhanced levels of NETosis (141).

PR3-ANCA and MPO-ANCA can cause NET formation in patients with AAV (139), however, the mechanism by which this occurs remains unclear. As discussed previously in this review, NETosis requires neutrophil activation, an event characterised by the respiratory burst, which was induced by crosslinking PR3-ANCA or MPO-ANCA to the cell surface (154). Furthermore, many factors released by neutrophils can activate the complement cascade (155-157), and several animal studies have shown that C5a-C5aR interactions can prime neutrophils for activation by ANCA $(136,158,159)$. C5aR1 may be a promising therapeutic target, as inhibition with antagonist CCX168 (Avacopan) has demonstrated efficacy in mediating disease severity (159). Other autoimmune studies have found that NETosis may be negatively regulated by the interaction between neutrophil semophorin D and plexin B2 on endothelial cells, this is further evidenced by the ability of recombinant plexin B2 in the blockade of NETosis in human cells.

\subsection{Rheumatoid Arthritis}

As discussed earlier in this review, NETosis is distinguished from other forms of cell death by the presence of citrullinated histones, a PAD4 mediated process. The involvement of PAD4 in the citrullination of histones was uncovered in animal models of rheumatoid arthritis (RA), where the presence of PAD4 and citrullinated proteins showed a positive correlation with disease progression (160). RA is characterised by the generation of autoantibodies against citrullinated proteins, which form immune complexes with citrullinated fibrinogen in the synovial tissue, resulting in the activation of macrophages (161). As citrullinated histones are found within NETs, as mentioned earlier on in this review, neutrophils undergoing NETosis may also become a target, therefore, any areas of local inflammation can become amplified with autoantibody binding and further amplification of injury. This process can become a self-perpetuating cycle, where autoantibodies targeting the citrullinated histones in NETs can also activate the complement system (162), releasing products from the complement cascade that prime neutrophils for NETosis, as discussed previously. This may provide an explanation for the accepted paradigm where complement activation at the site of autoantibody binding of citrullinated proteins can result in tissue damage (163).

NETs from RA patients induce stronger inflammatory response compared to NETs from healthy donors (86). Furthermore, neutrophils from RA patients showed increased spontaneous NET formation in vitro, with potential for elevated ROS production, increased NE and MPO expression, PAD4 mediated citrullination of H3. This was all abrogated with IgG depletion, but restored with an anti-citrullinated peptide antibody (164). Additionally, NETs from both healthy and RA donors were shown to activate resting macrophages, inducing the upregulation of human leukocyte antigen (MHC) class I/II and cluster of differentiation 86 (CD86) on the cell surface (86). Furthermore, NET stimulation of the resting macrophages induced the secretion of IL-8, IL-6 and TNF $\alpha$ (86), all pro-inflammatory cytokines that have been characterised to be dysregulated in RA and other autoimmune conditions (165-168), where antibodies targeting the latter two cytokines are currently used in the clinic for the treatment of RA (168, 169). Despite the pathogenic role of NETs in RA, Ribon and colleagues showed that they have anti-inflammatory effects on LPS activated macrophages, inhibiting the release of IL-6 (86). The authors concluded that NETs can trigger both pro- or anti-inflammatory effects depending on the target cell, its activation status and the stimulus (86). 


\subsection{Lung Disease}

While NETs in the pathogenesis of lung disease has been extensively characterised, recent research has provided evidence for its involvement in severe acute respiratory syndromerelated coronavirus (SARS-CoV-2) infection. A higher abundance of circulating neutrophils has been correlated with a worse clinical outcome in coronavirus disease 2019 (COVID-19) (170, 171). As NETosis is an important effector function of neutrophils under inflammatory conditions, it was not surprising that MPO and histone $3(\mathrm{H} 3)$, both NET components, levels were found to be elevated in the plasma, tracheal aspirate, and lung biopsies from COVID-19 patients $(172,173)$. Their neutrophils were capable of extruding more NETs, which were also larger than those produced by neutrophils from healthy controls (172). SARS-CoV-2 induction of NETs is dependent on angiotensin converting enzyme 2 (ACE2), serine protease, viral replication, and PAD4 (172). The release of NETs from the SARS-CoV-2 activated neutrophils was found to enhance the apoptosis of A549 cells, a human alveolar basal epithelial cell line (172), which can compromise lung function and lead to further disease progression.

Thrombogenic events have been documented in severe COVID-19 patients to induce lung damage (174). Significant deposits of complement components have been found in the pulmonary microvasculature of severe COVID-19 patients with respiratory failure (174). As discussed previously, the presence of complement elements can prime neutrophils for NETosis, with the addition of the cytokine storm observed in these patients (175), another NET inducer, it may not be unreasonable to assume that NETosis is contributing to microvasculature damage. This has been evidenced by a recent study, where NETs were found to colocalise with platelets in pulmonary vasculature from COVID-19 autopsies and disease severity correlated directly with MPO-DNA complexes (176). Furthermore, there was a significant elevation of platelet-derived factors such as PF4 and chemokine ligand 5 (CCL5 or RANTES) that activate NET formation (176). Another study characterised the interaction between COVID-19 and C5aR1, where MPO-DNA complex levels were found to correlate with thrombin/antithrombin (TAT) activity, suggesting activation of the thrombin axis (177). This neutrophil-platelet interaction is necessary for NET formation in thromboinflammatory disorders $(178,179)$, their presence was detected in aggregates in the circulation by Middleton et al. (176). Additionally, NETs have demonstrated thrombogenic activity in many inflammatory disorders via the expression of functionally active tissue factor (TF) (178). Skendros et al. found that platelet-rich plasmastimulated neutrophils induced the expression of TF mRNA, efficiently produced NETs bearing TF, which showed high TAT activity (177). As C5a is key mediator of neutrophil TF expression (180-182), Skendros and colleagues showed that selective blockade attenuated TF expression and functionality, inhibiting NET release (177).

\section{Role of NETs in inducing $T$ cell responses}

NETs are able to induce Th17 differentiation in a TLR2/MyD88 dependent manner. The phosphorylation of STAT3 is a crucial event in the activation of Th17 responses. As Th17 activation by NETs has been described extensively in psoriasis and pulmonary inflammation, the data from these studies will be utilised to shed light on the possible mechanisms that may be involved. 
Psoriasis susceptibility genes have been identified as tyrosine kinase 2 (TYK2) and TRAF3 interacting protein 2 (TRAF3IP2). Additionally, NETs promote Th17 induction, leading to IL-17 production, which binds to the IL17 receptor, activating the ubiquitin adaptor, Act1 $(\mathrm{NF} \kappa \mathrm{B}$ activator 1$)(183-185)$. This subsequently activates the NF $\kappa \mathrm{B}$ and mitogen-activated protein kinase (MAPK) pathways in target cells such as keratinocytes, epithelial cells and fibroblasts (185-187). A loss-of-function mutation in Act1, D10N, leading to the replacement of an aspartic acid (D) with asparagine (N), predisposes individuals to psoriasis (188-191). Wang et al. showed that Act1 is a client protein of the molecular chaperone, heat shock protein 90 (Hsp90). Subsequently, using Act-/- mouse models, they demonstrated that the Act1 D10N single nucleotide polymorphism (SNP) is defective, thereby leading to the loss of Act1 function (192). They went on to demonstrate a hyper Th17 response in Act-/- mice, with spontaneous development of IL-22-mediated dermatitis, providing a potential mechanism for the Act1 D10N mutation in psoriasis susceptibility (192).

NETs have been characterised to contribute to the overactive Th17 response in psoriasis pathology, with elevated levels found in the blood and lesions $(193,194)$. Lambert et al. used depletion experiments to investigate the role of NETs in the induction of Th17, showing that memory T-cells rather than naïve T-cells was the population from which the Th17 cells were derived (195). They went on to show that the Th17 phenotype was only induced when the memory T-cells were in physical contact with monocytes. Using donors with the Act1 D10N variant that produced spontaneous NETs, they showed that IL-17 release was more prominent in the homozygote genotype compared to wild type homozygotes. Furthermore, global gene expression analysis revealed a stimulatory effect of NETs on the Act1 D10N genotype, with enrichment of the "cytokine activity" gene set (195).

In pulmonary inflammation, the presence of free fatty acids (FFAs) has been characterised to induce NET release, resulting in acute lung injury through the production of ROS. Additionally, FFAs induced NETs are capable of activating dendritic cells (DCs), leading to CD4+ T cell differentiation into Th1 and Th17 cells, which release IL-1 $\beta$, IL-12 and TNF $\alpha$ (196). Akin to the cellular contact result demonstrated by Lambert et al., NET stimulated CD4+ primary $\mathrm{T}$ cells differentiated into Th1 and Th17 cells at a significantly higher rate when co-cultured with DCs compared to when CD4+ T cells were cultured alone (196). Zhang et al. used erythromycin to inhibit NET formation, downregulate Th1 and Th17 cells, effectively ameliorating disease in their emphysema model (197). 


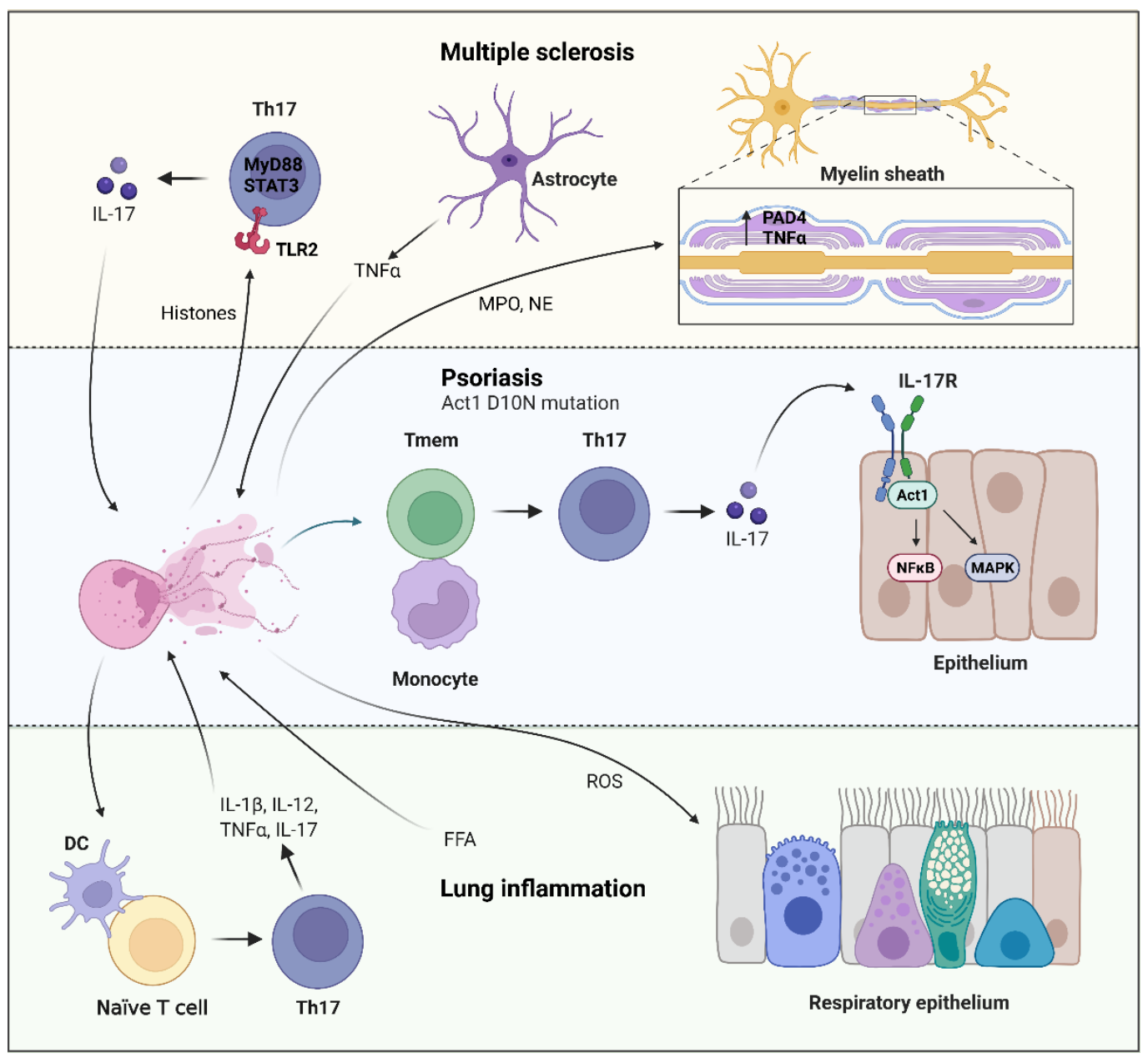

Figure 3. Neutrophil extracellular trap (NET) induction of T helper 17 (Th17) cells in disease. Multiple sclerosis (MS): Histones released from NETosis can directly trigger Th17 differentation via toll-like receptor 2 (TLR2) and myeloid differentiation primary response 88 (MyD88), activating signal transducer and activator of transcription (STAT3), which is critical for Th17 function $(263,264)$. The secretion of interleukin17 (IL-17) from the Th17 cells recruit more neutrophils (265), creating a proinflammatory feedback loop. Astrocytes can also release tumour necrosis factor $\alpha$ (TNF $\alpha$ ), which can prime neutrophils for NETosis (106), contributing to further local inflammation. Elevated myeloperoxidase (MPO) and neutrophil elastase (NE)DNA immune complexes have been shown to correlate with MS disease severity (107-110). Elevated nuclear levels protein arginine deiminase 4 (PAD4) and TNF $\alpha$ were detected before demyelinating disease. Psoriasis: Loss of function mutation in Act1, D10N, has been associated with disease susceptibility (188-191). With these individuals spontaneously generating NETs, which trigger memory T-cells (Tmem) that are co-cultured with monocytes to differentiate into Th17 (195). The IL-17 secreted by the Th17 cells bind to interleukin-17 receptor (IL-17R) and activates the ubiquitin adaptor Act1 (NFKB activator 1), subsequently triggering the nuclear factor $\kappa B(N F \kappa B)$ and mitogen-activated protein kinase (MAPK) pathways in target cells such as keratinocytes, epithelial cells and fibroblasts (185-187). Lung inflammation: Free fatty acids (FFAs) can induce NET release, leading to acute pulmonary injury via ROS production (196). These NETs can also activate dendritic cells (DCs), which can trigger the differentiation of naïve T cells into Th17 cells, releasing IL-1 $\beta$, IL12 and TNF $\alpha(196,198)$. 
NETs inducing Th17 differentiation has been shown to result in neutrophilia in severe asthma (198). Parallel exposure of mice to aeroallergen and endotoxin during sensitisation lead to the formation of NETs. These activated DCs in vitro to activate IL-17 production from naïve CD4+ T cells (198), unlike the differentiation process in psoriasis discussed previously, where Th17 cells are derived from memory T cells.

\section{Lymphocyte extracellular traps}

\subsection{B cells}

Recently, other leukocytes including B cells, T cells, natural killer cells and monocytes were reported to release mtDNA following stimulation with class C CpG oligodeoxynucleotides (CpG-C) and non-CpG-C, short, single-stranded synthetic DNA. This was independent of B cell antigen receptor, TLR9, STING and absent in melanoma 2 (AIM2) pathways, and did not involve an oxidative burst or result in cell death (6). CpG and non-CpG oligodeoxynucleosides of class $C$ were shown to induce B cells to extrude mtDNA, akin to the mitochondrial NETs formed by neutrophils. These were distinct from NETs due to their lack of antibacterial properties, instead with the purpose of acting as immediate activators of type I IFN production (6). Incubation of B cell mtDNA webs with peripheral blood mononuclear cells (PBMCs) induced the production of IFN $\alpha$. Akin to the vital form of NETosis, the B cells remain viable following mtDNA release (6). Arrieta et al. also characterised the release of DNA from B cells following treatment with serum from patients with SLE, Sjögren syndrome (SS), cryoglobulinaemia, and from one individual with cryoglobulinaemic vasculitis (7).

\section{$5.2 \mathrm{~T}$ cells}

As part of the extracellular trap (ET) study conducted by Arrieta et al. discussed above, T cells were also found to release DNA following stimulation with serum from SLE patients (7). CD4+ T cells were characterised by Costanza et al. to release histone-coated DNA fibres in a ROS dependent manner following treatment with anti-CD3 and anti-CD28 antibodies (8). The authors termed the extracellular DNA threads 'T helper-released extracellular DNAs' (THREDS). They subsequently showed that THREDS were able to induce IL-2, GM-CSF, IFN $\gamma$, and TNF $\alpha$ production from naïve CD4+ T cells (8), amplifying the inflammatory response. As discussed previously in this review, NET deposits have been found in the CNS, as acknowledged by Costanza et al. in this study, following which they used the experimental autoimmune encephalomyelitis (EAE), a CD4+ T cell-mediated MS model to investigate the therapeutic potential of mitochondrial ROS blockade using SKQ1. Splenocytes from treated mice showed reduced production of proinflammatory cytokines, GM-CSF, IFN $\gamma$, and IL-17A compared to the control group. Furthermore, histopathological analysis revealed significantly less immune cell infiltrate and demyelination in the treatment group (8).

Koh et al. also used anti-CD3 and anti-CD28 antibodies as stimuli to show extrusion of ETs from CD8+ T cells, which they termed 'lymphocyte extracellular traps' (LETs) (9). They used confocal time-lapse microscopy to show that the fibrous structures connected the LETreleasing cell to adjacent cells, followed by death of target cells via the delivery of cytolytic vesicles. The authors went on to investigate the involvement of LETs in tegumentary leishmaniasis, a parasitic disease where CD8+ T cells play a central role in pathogenesis (199-201), as previous studies have found NET deposits in leishmaniasis skin lesions $(202,203)$. Using confocal microscopy, they colocalised DNA strands with cytolytic vesicles and correlated disease progression with increased overall LETs (9) 


\section{Extracellular Traps are no longer the strict domain of Neutrophils}

\subsection{Eosinophils}

Eosinophils are bone derived innate immune cells that make up 1-6\% of the circulating blood under normal homeostasis. In contrast to neutrophils, eosinophils are larger $(12-17 \mu \mathrm{M}$ in diameter) and are readily identifiable by large specific granules which stain with eosin (hence the name Eosin-ophil). The nucleus is bilobed and easily identifiable with Electron microscopy but is often obscured by granules under the light microscope (204). Eosinophils are largely recruited as a main line of defense against parasitic helminths, and are heavily involved in allergic responses secreting preformed Th2 cytokines such as IL-4. Unique to eosinophils is the large crystalloid granules which are large and contain preformed proteins: Eosinophilic peroxidase (EPO), major basic protein (MPB), eosinophil-derived neurotoxin (EDN), as well as cytokines (IL-2,-3-,4,-5,-6,-10 and -12, TNF $\alpha$, IFNy to name a few from an exhaustive list).

DNA extracellular traps released from eosinophils were first described by Yousefi et al., in 2008 (205) where extracellular DNA fibres were fund to be "catapulted" after eosinophils were activated with either IL-5,or IFN $\gamma$ and subsequently stimulates with LPS or C5a. The DNA was of mitochondrial origin and did not result in the death of the eosinophils. This left the question: "is this preformed in granules" or of nuclear origin? DNA released from eosinophils was observed in under a second, and was more than twice the size of the diameter of the cell. No evidence of apoptotic cell death was observed [using both phosphatidylserine (PI) redistribution or caspase 3 activation], clearly distinguishing the ET release from other forms of cell death. The release appeared from peri nuclear structures rather than the nucleus itself indicating a probable mtDNA location as the source of DNA. PCR investigation confirmed that the DNA was of mitochondrial source rather than nuclear.

After this initial report by Yousefi et al. further reports on eosinophil extracellular traps were published and the term ETTosis or EETs was coined to describe this type of eosinophil cell death. Two types have been described very similar to what is seen in neutrophils vital and suicidal.

\subsubsection{Vital EETs}

Vital EETs release mitochondrial DNA studded with the protein MBP and ECP. This form of DNA release does not result in the death of the cell. As described previously above, mtDNA is released, there is no evidence of cytoskeleton remodelling as seen in NETs or in suicidal EET formation. However, what the two forms of DNA release do have in common is a dependence on the NADPH complex and ROS production. In asthma, EETs are significantly more evident than non-asthma patients (10). The DNA observed was determined to most likely be of mitochondrial origin as mitochondrial ATP synthetase subunit 6 was found on the extracellular DNA eosinophil strands. Further evidence this form of EET did not result in the death of the was determined by cell death assays using TUNEL which determined that the eosinophils in asthmatic biopsies had not undergone cell death and the extracellular DNA combined with eosinophil proteins was generated by active live eosinophils.

\subsubsection{Suicidal EETs}

The first report of EETs that resulted in the death of the cell was in 2013 by Ueke et al., (206). Human eosinophils stimulated with either IgG, IgA, PMA, GM-CSF (+Platelet activating Factor (PAF), A23187 and IL5 +PAF all resulted in a lytic form of eosinophil cell death. EETs were clearly distinguishable from other forms of cell death such as necroptosis and apoptosis as no filamentous DNA was released. To determine if like neutrophils EETs formation relied on NADPH oxidase, eosinophils were stimulated in the presence of the NADPH oxidase inhibitor DPI, and no EETs were observed, confirming EET formation is NADPH dependent. It is 
likely that the difference in the types of DNA release are related to the stimulus, some stimuli may activate pathways that promote the release of mtDNA, whereas other stimuli promote cell death.

\begin{tabular}{|l}
$\begin{array}{c}\text { Innate Extracellular Traps } \\
\text { Traps (MCETs) }\end{array}$ \\
$\begin{array}{c}\text { Eosinophil Extracellular } \\
\text { Traps (EETs) }\end{array}$ \\
$\begin{array}{l}\text { Basophil Extracellular } \\
\text { Traps (BETs) }\end{array}$
\end{tabular}

Figure 4. Innate extracellular traps. Mast cell extracellular traps (MCETs, purple) are stimulated by a range of pathogens including bacteria, Fungi, PMA and Hydrogen Peroxidase. Once formed MCETs, consist of both nuclear DNS, mitochondrial DNA, histones and mast cell specific granules, tryptase and chymase. Eosinophil extracellular Traps (EETS, green), are simulated by bacteria, LPS, immobilised IgG and IgA, cytokines, Il-5, PMA and Calcium ionophore. Webs of DNA contain are of both nuclear and mitochondrial origin, with histones and ROS. Basophil extracellular traps (BETS, blue) are activated by bacteria and the cytokine IL-3. NET constituents are similar to that of EETS. Macrophage/Monocyte (METs, red) are activated by bacteria, PMA, hydrogen peroxidase, and cigarette smoke. The webs contain, nuclear DNA, myeloperoxidase, proteases: MMP9 and MMP12 and citrullinated histones.

\subsubsection{Are EETs protective or pathogenic?}

EETs provide protection against fungi and bacteria by ensnaring pathogens in their large filamentous webs. Il-5 transgenic mice constitutively express IL-5, and results in excessive recruitment of blood eosinophils (40\% of leukocytes compare to homeostatic conditions of less than $2 \%$ ). Yousefi et al., used these mice to induce sepsis via a caecal ligation puncture (CLP) model, where eosinophils were recruited rapidly to sites of intestinal inflammation whereby they release EETs (205). This phenomenon requires eosinophils to be activated by IL-5 as the WT mice had little evidence of eosinophilia or ET formation. The IL-5 transgenic mice were protected over time after CLP, with a significant reduction in proinflammatory cytokines and bacterial burden. This provided proof of concept data that eosinophils may be required to "plug' up breaches in the intestinal barrier thereby providing protection against sepsis. However, this could be a double edged sword, and the recruitment of eosinophils may also induce 
inflammation. In inflammatory bowel disease (IBD) eosinophils are proinflammatory, where they contribute to diarrhea (as a promotility agent), contribute to tissue pathology in particular damage of the epithelial cells, and promote fibrosis (207).

The role of eosinophils in allergy and airway diseases are well known. Severe eosinophilic asthma (SEA), acute asthma, chronic eosinophilic rhinosinusitis (ECRS) and eosinophilic otitis media (EOM) are characterized by eosinophil infiltration and have been observed to have abundant EETs at sites of inflammation.

In SEA, blood eosinophils stimulated ex vivo with either IL-5 or LPS had significantly more EETs when compared to patients with non-severe asthma (NSA). EETs behave in an autocrine fashion where they induce eosinophil granulation. Incubation of EETs remnants with eosinophils induced robust EET formation and increased ROS production (208). EETs when cocultured with epithelial cells (A549 cells, lung carcinoma epithelia cell line) resulted in 10\% of the epithelia detaching from the culture well surface, increased epithelial cell permeability and the production of IL- 8 and IL- 6 release for the epithelial cells. This is a strong indication that the granules released in EETs are involved in perpetuating the airway inflammation observed is SEA patients (208).

In an animal model of acute asthma, EETs have been observed in bronchoalveolar lavage fluid (BALF). DNase I treatment in mice with induced asthma (induced by subcutaneous sensitization with OVA and subsequent intranasal challenge with OVA), reduced EETs and decreased airway resistance significantly (209). It cannot be discounted that the removal of the mucus in the airways by DNase I, rather than the EET degradation accounted for the protective effect in this model of disease. DNase I is currently used to treat patients with cystic fibrosis to remove the mucous in the airways (210). More work is needed to clarify if the DNase I is specifically clearing the observed EETs.

EETs have been found as predominant components of exudate from patients with ECRS and EOM $(211,212)$. In chronic eosinophilic rhinosinusitis (ECRS) it is proposed that nasal carriage of staphylococcus aureus is inhibited by EETs which release mitochondrial DNA and ensnare the bacteria. In co-cultures S aureus is able to induce EETs and prevent its growth (213). Migration assays demonstrated that EETs migrate towards S. aureus and in particular migrate towards areas of epithelial disruption where S. aureus was trapped. Those patients with high levels of IL-5 in tissue had significantly more EETs present. These results suggest that eosinophils are recruited to sites of epithelial damage to provide host protection from $\mathrm{S}$. aureus. It is possible that EETs may be required to maintain barrier function, to prevent pathological bacterial infections.

Eosinophilic Otis Media (EOM) is a middle ear disease characterized by eosinophils and eosinophilic mucus within the middle ear mucosa which causes hearing impediment. It is refractive to most treatment with the exception of steroid treatment which has large undesirable side effects (214). A recent study has shown the EETs are a major feature of middle ear effusions, staining for EETs demonstrated that they were present in all patients. Combined with clinical evidence of high IL-5 cytokine production in these patients indicates that IL-5 released from eosinophils, recruits more eosinophils which ET and contribute to the viscosity of the mucus (214).

EETs have recently been shown to have a role in the pathogenesis of ANCA associated vasculitis (AAV) (215). In a study of 35 patients with AAV [(10) EGPA, (13) MPA, (12) GPA] those patients with EGPA only had significant serum cell free nuclear DNA and cell free mitochondrial DNA that associated with disease activity. In particular levels of cf-DNA and cfmtDNA were associated with the Birmingham Vasculitis Activity Score (BVAS, BVAS is an assessment tool which measures disease activity in patients). EETs were observed around small vessel thrombi in skin samples, and eosinophils were occluding blood vessels. 
Eosinophil isolated from the blood were stimulated to ET in vitro and compared to NET formation by neutrophils. In comparison to NETs, ETs had condensed chromatin threads rather than the decondensed chromatin observed in NETs with an increased structural stability. DNase I was able to dissolve NETs readily whereas the stable structure of the ETs protected them from DNase I treatment. Little is known about the pathogenesis of EGPA and these observations indicated therapy targeting eosinophils and ETs may be of therapeutic benefit for patients (eg IL-5 antibody treatment).

\subsection{Mast cells}

Paul Ehrlich and Elie Mitchnikoff received the Nobel Prize over a century ago in recognition of their contribution to the field of immunology. Mast cells (MCs) were first described in Ehrlichs doctoral thesis who named them "Mastzellen" cells, "mast" in German means fattening, and Ehrlich thought the role of mast cells was to nourish the surrounding tissue through release of the large granules. Elrichs discovered that mast cell granules specifically reacted metochromatically to aniline dyes, one of the methods still used to identify mast cells to day. Elrich, observed the presence of mast cells in chronic inflammation and tumours, and concluded they were there to nourish the tissue (216). This we now know to be incorrect, but the actual function of mast cells eluded many scientists after Elrich, and to this day mast cells have been shown to be multi-faceted. They play a traditional role in innate immunity (helminth parasites), a role in allergy, and more recently have been shown to have immunomodulatory functions.

MCs are derived from CD34+/c-kit+/FceRI- pluripotent progenitor cells. MCs have a long life, and are found in many organs throughout the body, but are most commonly found in skin and mucosal surfaces. MCs only mature once they are recruited into tissue, where they have the capacity to develop into a heterogeneous population. MC plasticity, has recently been attributed to the diverse transcriptional properties of mast cells, which are distinct from other lymphoid and myeloid cell populations. Expression profiling of MCs, demonstrated that MCs are enriched in transcriptions for genes for a wide variety of proteases, sensing genes, and genes involved in metabolic pathways. Genes between the different tissue types of MCs differed widely, evidence that MCs can respond to their environment (217). Once recruited from circulating blood into the tissues, MCs differentiate into different types of mast cells based on their location and granule content. In humans MCs develop into 3 different subtypes of mast cells, Mast cells that are positive for tryptase (MCT), chymase (MCc) and double positive for both tryptase and chymase (MCTC) (218). In mice, MCs are subtyped according to their location and heparin content within their granules. Connective tissue MCs (CTMC) which contain ample heparin containing granules and mucosal mast cells (MMCs) where heparin is either absent or minimal (219).

The role of MCs in allergy has been well studied, especially in IgE mediated allergic disease. Mast cell activation in the context of allergy, is regulated through FceRI a high affinity receptor for IgE (220). Antigen specific IgE is produced by B cells in response to antigen presentation by DCs. IgE binds to FceRI on the MC surface, activating the cell to degranulate, which releases a multitude of different proteases (chymase, tryptase), histamine, serotonin, heparin and secrete cytokines, all within minutes of exposure to the antigen (221).

MCs are also now been recognised to play a role in adaptive immune responses. In vitro experiments on bone marrow derived mast cells BMMC, demonstrated that TLR4 engagement of MCs induces the secretion of cytokines and chemokines cytokines such as IFN $\gamma$, IL-6, IL-4, IL13, TNF $\alpha$, IL-5, instead of the release of histamine as TLR2 elicits (222). These MC derived cytokines can influence the polarization and activation of $\mathrm{T}$ cell subsets. CD4+ T cell effector functions can be regulated by MCs. IFN $\gamma$ primed MCs under inflammatory conditions in human psoriatic skin can present antigen to CD4+ memory $\mathrm{T}$ cells, and skew the $\mathrm{T}$ cell response 
to an IL-22 response. MCs are often observed in close contact with T cells in psoriatic skin, where they are well placed to perpetuate inflammation (223).

\subsubsection{Mast cell extracellular traps}

Mast cell extracellular traps (MCETs) can be stimulated by a wide variety of stimuli, but they are very similar to what induces NETs, namely PMA, hydrogen peroxide (H2O2) and in response several different pathogens including bacteria, protozoa, and fungi (224). Like NETs, MCETS contain long strands of DNA decorated with mast cell granules, many of which have anti bactericidal killing capability such as $\beta$ defensins, LL-37 and piscidins (224). Like neutrophils they also require ROS dependent mechanisms.

In the context of infections Mast cells are often the first responders that release enzymes that recruit other immune cells such as neutrophils and macrophages. The first description of MCETs was in the context of Streptococcus pyogenes an opportunistic bacteria that causes major skin infections such as impetigo and necrotizing fasciitis. In this study it was observed that mast cells were able to restrict the growth of bacteria independent of phagocytosis (225). Regardless of whether the mast cell was of human or murine origin, incubation with Streptococcus pyogenes induced MCET formation, and Streptococcus pyogenes was observed trapped in the filamentous DNA extruded from the mast cells. The entrapment of Streptococcus pyogenes within the DNA killed the bacteria (observed by live/dead stain). Unlike NETs which can be inhibited with DNase I, MCETs required co-incubation with both DNase I and myeloperoxidase (MPO) to inhibit ET formation. The addition of MPO targets the tryptase within the NETs as it is a potent inhibitor of mast cell tryptase (226).

MCETs also inhibit the growth of staphylococcus aureus in the initial phase of infection. Staphylococcus aureus causes skin infections, pneumonia and can induce septicaemia (227). Staphylococcus aureus strains have developed that are resistant to treatment via antibiotics, therefore understanding mechanisms in which the host can defeat this pathogen are important. In the case of mast cells in Staphylococcus aureus infection they are both protective and pathogenic during an infection. In protection mast cells release MCETs which have an antimicrobial effect killing the bacteria they trap both within the DNA and via release of antimicrobial compounds released from mast cell granules. The pathogenic effect is that Staphylococcus aureus is able to internalise within the mast cells in a subterfuge manner where it avoids detection and elimination. Live Staphylococcus aureus can be found up to 5 days later viable within mast cells (227).

MCET formation is stimuli dependent (228). DNA release from mast cells can be independent of ROS production depending on the response of mast cells to different pathogens. ROS production and extracellular DNA release measured via FACS analysis has shown that both L. Monocytogenes and S. aureus can release DNA independent of ROS production (228). It is possible that this observation may be similar to what is seen in other leukocyte cell populations and may be a form of "vital" release of extracellular DNA early on in exposure to the pathogen. Late exposure of L. Monocytogenes to Mast cells can also induce "suicidal" ET release.

Group A streptococcus (GAS) causes skin infections, glomerulonephritis (acute kidney injury), pharyngitis, sepsis and endocarditis (229). GAS can also induce MCET formation, mediated through M1 protein. M1 protein is a critical virulence factor that contributes to the pathogenicity of GAS. M protein promotes survival of GAS and replication by interacting with serum proteins (C3b) within human blood blocking opsonisation of the bacteria. M1 mutant mice have significantly reduced capacity to produce NET and MCETs, suggesting that M1 is enough alone to induce MCET formation (229). 
C. albicans is one of the most common opportunistic fungal infections in humans. In homeostasis conditions $C$. albicans is a commensal which habitats' in skin and mucosal surfaces (urogenital, gastrointestinal and the oral cavity). Immunosuppressed patients in particular are at risk as C.albicans can invade non commensal tissue and manifest a pathogenic response in tissue. Mast cells which are predominant in mucosal surfaces are the first innate cell to come into contact with C.albicans where degranulation can inhibit and restrict the growth of C.albicans (230). C.albicans can also stimulate MCET formation but not inhibit the growth. After 6 hour incubations with C.albicans mast cells release extracellular DNA in a suicidal fashion, with the release of nuclear DNA, histones and enzymes. However, this does little to inhibit the growth of the fungus- the reduction in C.albicans is actually attributed to the release of mast cell granules. The only function of MCETs in the context of C.albicans infection is in providing a physical barrier in which the fungus is trapped.

MCETs may play a role in limiting bacterial growth but also have a dark side. In inflammatory conditions such as psoriasis, Mast cells that release MCETs also release large quantities of IL-17a, a proinflammatory cytokine which recruits neutrophils (194). Mast cells within the papillary dermis of psoriasis plaques not only degranulate but also form MCETs, with large strands of extracellular DNA containing large quantities of IL-17. In an ex vivo model of normal human skin explants IL-1 $\beta$ and IL-23 can induce MCET formation (194). This suggests that in inflammatory conditions, release of proinflammatory cytokines from damaged epithelial cells and leukocytes recruited to the skin (eg T cells and neutrophils) have the potential to activate tissue resident Mast cells to form MCETs, perpetuating the vicious cycle of inflammation.

MCETs are associated with the pathogenic progression of thrombus formation in patients with thrombotic complications after myocardial infarction (231). Autopsy material of the thrombus from patients have significant numbers of NETs, EETs, METs and MCETs. Although the number of NETs and METs outweigh the number of EETs and MCETs. MCETs observed within the plaques is of concern even in small numbers as they have the power to destabilize the plaque through release of proinflammatory cytokines and the release of enzymes, in particular mast cell specific histamine, chymase and tryptase (231).

\subsection{Basophils}

Basophils comprise less than $0.5 \%$ of the white blood cells and are largely associated with playing a role in allergic diseases and in response to infection with parasites. Like Mast cells they share the unique ability to release inflammatory cytokines and enzymes that instigate inflammation in allergic inflammation (232). The function of basophils is controlled by the cytokine IL-3, it promotes both differentiation and survival and primes basophils to release leukotriene C4. Priming basophils with IL-3 can stimulate Basophil extracellular traps (BETs) in a concentration dependent manner. This requires cross linking of the high affinity IgE receptors. If these receptors are blocked no BET formation is observed. After cross linking IgE receptors, basophil mitochondria and granules track toward the outer cell membrane. The nucleus stays intact, and histones are not observed on the extruded DNA indicating that is likely to be of mitochondrial origin and not nuclear. This is a NADPH ROS independent mechanism as basophils lack components critical for the NADPH complex ( p47phox and p67phox). Instead mitochondrial ROS provides the energy required for DNA released. Further evidence of mtROS instigating the process is that MitoQ an inhibitor of mtROS prevents the formation of BETs.

Both E.Coli and S.Aureus also stimulates BET release, through a NADPH independent mechanism. Basophils co-cultured with both E.Coli and S.Aureus stimulate the release of mtDNA whilst the nuclear DNA stays intact within the cell. E.Coli and S.Aureus trapped with the DNA of BETs is actively killed, suggesting that BET formation is a further mechanism for host defence against bacterial infection (13). 
Monocytes are generated from hematopoietic stem cells in the bone marrow. Monocytes migrate from the circulating blood stream into the tissues where they differentiate into macrophages. The primary function of macrophages is host defence, through phagocytosis of microorganisms, clear cell debris from cell death (apoptosis, NETs, Necrotic cells etc.) and initiate tissue repair and healing. Macrophages are also able to present antigen to T helper cells via MHC class II molecules. In inflammation macrophages can be divided into either M1 or M2 macrophages based on their phenotype. M1 macrophages (also known as classically activated macrophages) are generated in response to IFN $\gamma$ and LPS and are considered to be pro-inflammatory as they secrete IL-12, and IL-23. M2 macrophages (alternative macrophage activation) are induced by IL-4 and IL-13, and preferentially secrete IL-10 over IL-12.

\subsubsection{Macrophage extracellular traps (METs)}

Haemophilus influenzae (NTHi) is a commensal bacteria present in the pharynx of adults in normal homeostatic conditions. However, NTHi can move further down the airways and take up residence in the lower respiratory track in patients with chronic bronchitis and chronic obstructive airway disease (COPD)(233). Macrophages from patient bronchial alveolar lavage (BAL) fluid samples produce ROS when stimulated with NTHi, and extrude large nuclear extracellular DNA strands of DNA similar to what is seen in NETs. These structures termed macrophage extracellular traps (METs) are decorated with MMP12, and citrullinated histones. The release of proteases by METs have the potential to exacerbate conditions such as emphysema where MMP12 has already been established to play a role in the progression of disease (233). In vitro NETs and METs from BAL fluid can be inhibited with DNase I, suggesting a possible therapeutic avenue for treatment for patients.

Cigarette smoke is a critical cause of lung disease, playing a role in chronic inflammation which can manifest clinically as emphysema and COPD. Cigarette smoke causes a sustained production of proteases and exhausts the endogenous supply of alpha- 1 antitrypsin (AAT) the natural inhibitor of neutrophil elastase (234). Cigarette smoke induces alveolar MET formation in vitro where they express both MMP9 and MMP12 which colocalise with extracellular DNA citrullinated histones and PAD2. In contrast to NETs, alveolar METs in the study extrudes shorter strands of DNA but like NETs had high expression of ROS. Using a smoked mouse model, the number of macrophages recruited to the lungs was 2 fold that of mice not exposed to cigarette smoke. Mice exposed to cigarette smoke and treated with DNase I had significantly less macrophages, whereas DNase I had little effect on the recruitment of neutrophils. Exposure to cigarette smoke resulted in 5x the amount of production of METs when compared to NETs. Suggesting that macrophages are more sensitive to activation by cigarettes smoke than neutrophils.

Children experience frequent respiratory infections which may be detrimental to the development of healthy lungs. Children unlike adults are not as effective at clearing these infections. BAL samples from 76 patients of children with lung disease (38, Cystic Fibrosis and 38 subject non cystic fibrosis) were examined ex vivo for extracellular trap formation. NETs were more prevalent than MET formation however when stimulated with NTHi significantly increased the numbers of both NETs and METs (235). Combination of both DNase I and alpha-1 antitrypsin (AAT) produced a significant reduction in the number of NETs and METs (20x fold) compared to either treatment used alone. Interestingly DNase I alone increased neutrophil elastase activity, presumably as NE is protected within the DNA strands of extracellular traps, which is released when DNase I is added.

Escherichia coli and Candida albicans induce MET like structures in J774A.1 macrophage cell lines and peritoneal lavages (236). METs contained both nuclear and mtDNA and were decorated with enzymes and histones. MET formation was independent of ROS produced by NADPH, and had limited ability to kill the bacteria (55\% effective) or fungus (18\%) ensnared in their traps. Additional stimuli were used to induce MET formation such as LPS, PMA and 
$\mathrm{H} 2 \mathrm{O} 2$ which are potent NET stimulators, however failed to induce METs. This is in direct conflict with other reports that have shown MET formation with these stimuli and that MET production is dependent on NADPH ROS $(11,237)$. This could be due to the type of cells being used are not as effective at inducing MET formation, with one being a cell line and the other cells from peritoneal lavage fluid.

The first description of macrophage extracellular traps (METs) in autoimmune disease was the observation of (METs) within the kidney glomeruli of patients with MPO-ANCA associated vasculitis (133). Macrophages are the predominant cell type within kidney biopsies. MPO the autoantigen in this disease is thought to of been released mainly by neutrophils either through degranulation or the production of NETs. This study demonstrated that there were equal numbers of MPO positive macrophages compared to MPO positive neutrophils, suggesting that macrophages, and subsequent METs may be an overlooked additional mechanism in which MPO is deposited in the kidney.

Like observed in NETs, there are still many discrepancies in the literature regarding the formation of METs. This could also be due to different types of cell death with those being NADPH ROS dependent being "suicidal" MET formation and those independent of NADPH ROS being "vital" relying on mtROS. There are still studies that need to be conducted to examine if different sub types of macrophages are more susceptible to forming METs than other cell types (eg M1 vs M2). The pathways that lead to MET formation have not been as well characterised as that of NET formation, with many questions remaining on what drives the macrophage to MET formation.

\subsection{Dendritic Cells}

Dendritic cells (DCs) are professional antigen presenting cells (APCs), derived from hematopoietic bone marrow progenitor cells. Their primary function is to present antigen proteins from micro-organisms to T cells. Immature DCs reside in the epithelia such as skin, whereas mature DCs reside in the lymph nodes and spleen. DCs can be divided further into two subsets, known as classical and plasmacytoid. Classical DCs are present within epithelia, peripheral tissue, and lymphoid organs. Plasmacytoid DCs are present both in the tissue and blood and they are the primary producers of type 1 Interferons.

Very little data is available on the formation of dendritic cell extracellular traps. One report describes the release of extracellular DNA by plasmacytoid DCs after incubation with A. fumigatus (238). After a 4 or 6 hour incubation of pDCs with A. fumigatus extracellular DNA could be observed containing citrullinated histones and spread over the A. fumigatus area. The percentage of DC ETs was approximately $1 \%$ which is comparable to other studies that show neutrophils NET in response to other fungi (Candida albicans) at the same rate (239). The study does not examine if the release of DNA inhibits or kills A. fumigatus. More work needs to be done to see if this response is detrimental to the host or if it functions as a critical part of host protection.

\section{Potential Therapy targeting the injurious functions of extracellular traps}

The evidence that NET/ETs can drive proinflammatory pathologies is extensive, consequently they are promising targets for new specific alternative therapy to broad spectrum immunosuppressive agents. Current immunosuppressive agents such as Cyclophosphamide and broad spectrum corticosteroids are associated with adverse side effects and have no specificity. The advantage of most of the inhibitors of ETs is that they are reversible and can be temporarily withdrawn if patients contract an infection that require ETs to efficiently clear it. In contrast 
current conventional treatment if halted can take weeks to months before the immune system is restored.

All the leukocyte extracellular traps described within this review have different mechanisms of action and effectiveness against different human pathogens, however they all have similar pathways to extracellular trap formation providing different avenues of possible therapeutic strategies. 1) Target the extracellular traps themselves once expelled by digesting the ET remnants (DNase I). 2) Target enzymes required for digesting either the nuclear envelope, outer cell membrane or citrullination of histones (PAD family, NE, MPO, GASDERMIN D). Each of these distinct critical components will be considered and discussed briefly as more diverse treatment options have been extensively reviewed recently $(240,241)$.

\subsection{Therapy that targets extracellular traps after formation}

\subsubsection{DNase I}

DNase I is the most commonly used enzyme to disrupt NETs both in vivo (in animal models of inflammatory diseases) and in vitro. It is a safe choice as it is already used clinically to treat patients with cystic fibrosis, and is well tolerated with few side effects, so is readily poised for translation to other diseases $(210,242)$. DNase I belongs to a large family of DNases comprising DNase I, DNase 1L1, DNase 1L2, and DNase IL3 (243). DNase I and DNase L3 both show potential in target ET driven pathologies. The two enzymes work synergistically, with DNase I targeting double stranded DNA (dsDNA) and extracellular nuclear proteins. DNase 1L3 plays more of role in degradation of intracellular DNA, nucleosomes and DNA protein complexes (244). Both enzymes degrade NETs, and there are multiple reports on DNase I disrupting METs, MCETs, and EETs already reviewed in the previous section.

The major issue with DNase I as a therapy is its relatively short half-life of 3-4 hours, and its rapid inactivation by $\mathrm{G}$ actin in the circulation. Multiple patents are already in place to protect research developing actin resistant DNase I for the treatment of cystic fibrosis to combat this issue (NCT02605590, NCT02722122). Other avenues to increase the half-life of DNase I are experimental, using cutting edge technology. Gene delivery vectors have already been used in animal models of sepsis where plasmid expression of both DNase I and DNase 1L3 have been shown to maintain stable therapeutic levels of DNase (244).

\subsection{Therapeutic targeting of critical enzymes required for ET formation}

\subsubsection{Peptidyl Arginase Deiminases}

PAD4 is a critical enzyme that citrullinates histones by converting a positive arginine to a negative citrulline residue. This has a dramatic effect on cell signalling, inducing chromatin decondensation which facilitates the expulsion of nuclear DNA (245). There are 5 different PAD enzymes, PAD 1, 2 and 4 are expressed in the immune system, as well as other tissue whereas 1, 3 and 6 are expressed in tissue only. A common requirement of all PAD enzymes is calcium dependent catalysis, where intracellular calcium concentrations have to rise above homeostatic conditions to promote activity. PAD4 is largely associated with the production of NETs, and is less observed in other forms of ET formation. PAD2 has been associated with MET formation. The role of PAD expression is not well defined in EETs, MCETs and BETs.

Therapeutic targeting of PAD4 has been well explored in many inflammatory conditions. The main therapeutic focus is on various forms of chlorine amidine which inactivates all the PAD isoforms. Cl-amidine and BB-Chlorine amidine have been explored extensively in the context of autoimmune kidney diseases, showing protective effects in lupus, where it inhibits 
NET formation and reduces proteinuria (clinical indicator of renal function) whilst also protecting against skin inflammation $(246,247)$. Therapeutic use of $\mathrm{Cl}$-amidine also provides protection in a model of murine sepsis, where overall survival is improved through the inhibition of NETs (248). In murine atherosclerosis Cl-amidine can reduce vascular damage and modulate innate immune responses (through a reduction in macrophages in arteries) (249).

Inhibition of PAD4 is not without concern. Citrullination of histones in NET formation is not the only physiological function it performs. PAD enzymes also play a role in gene regulation and cell differentiation (250). Inhibition of PAD4 is also deleterious in certain forms of bacterial infection. PAD4 -/- mice are more susceptible to infection in models of necrotizing fasciitis, as NETs are required to efficiently clear S.flexneri and Group A Streptococcus (GAS). Pathology in PAD4-/- mice infected with GAS was quadruple of that seen in WT mice (251).

\subsubsection{Neutrophil elastase inhibition}

A promising therapeutic avenue is the inhibition of neutrophil elastase (NE). NE plays several different role in the formation of NETs. Firstly, it migrates to the nuclear envelope where it helps break down the nuclear membrane, and cleaves histones. Secondly, NE cleaves GASDERMIN D activating it to create pores in the outer cell membrane to allow expulsion of nuclear DNA. Inhibiting any of these functions will inhibit NET formation. In terms of the proinflammatory role NETs play, the DNA backbone of the NET shields NE from endogenous inhibitors providing an injurious reservoir of proteases that directly injure tissue.

Neutrophil elastase inhibitors are already well developed clinically with multiple clinical trials in various stages for treatment of inflammatory lung diseases such as cystic fibrosis, COPD and bronchiectasis (252-254). Both Alvelestat (AZD9668) and BAY 85-8501 are the leading candidates, they are both reversible and have similar potency to that of endogenous antiproteases. Importantly both have been shown to inhibit NETs in vivo and in vitro (255).

\subsubsection{Gasdermin}

As mentioned previously Sollberger et al (59), demonstrated that neutrophil elastase cleaves Gasdermin D, which punches holes in the nuclear envelope and outer cell membrane to facilitate the release of extracellular DNA. Using a chemical screen to identify potential inhibitors of NETosis, the authors found a compound that both inhibits the inflammasome and NET formation-LDC7599. Through elegantly designed experiments Sollberger et al demonstrated that GSDMD was required for NETosis (using GSDMD mutant mice NET formation was significantly abrogated). LDC7599 is still clinically an experimental drug, but shows therapeutic potential.

Disulfiram is currently used therapeutically to treat alcoholism. Disulfiram inhibits aldehyde dehydrogenase irreversibly preventing ethanol conversion into acetaldehyde, which causes adverse effects when taken with alcohol causing nausea and tachycardia powerful deterrents to reduce alcohol consumption. Hu et al, (256), discovered using a high-throughput biochemical screening that disulfiram can inhibit GSDMD pore formation. Therefore, it stands to reason it will also block NET formation.

As already discussed NET formation is a prominent feature of lung pathology in SASCoV-2 Infection. Using a rodent infection model of SARS-CoV-2 it has been shown that disulfiram can significantly reduce NET formation and increase survival demonstrating its therapeutic potential (257). As disulfiram is FDA approved and is well tolerated clinically it is well poised for translation to treat NET driven pathologies. A clinical trial has already commenced to evaluate the efficacy of disulfiram in treating patients with Moderate COVID-19 (NCT04594343). 


\section{Conclusion}

Extracellular trap formation from innate immune cells has likely evolved to enhance host defence. Historically humans prior to the industrialisation of the world and modern medicine would have needed extracellular traps to help reduce infection. Akin to the redundancy of an appendix, this innate mechanism is a vestigial hangover from a time when living conditions and modern medicine were lacking. The evidence suggests that extracellular traps are now more harmful contributing to inflammation and pathology in a range of diseases. In autoimmunity NETs alone release over 70 known autoantigens. Given many current treatments for inflammatory diseases are non-specific, targeting NETs/ETs may provide a specific treatment to reduce the burden of disease with minimal side effects. This expanding field of cell death and immunology still has questions left unanswered. It is still unknown why a leukocyte is driven down the pathway of extracellular traps or why some stimuli are potent stimulators of extracellular traps and others are not.

No clinically approved specific therapy to target NETs/ETs currently exists. The majority of the inhibitors discussed here, are already used clinically to treat other inflammatory diseases so are reasonable candidates to put forward for treatment of diseases were extracellular traps are prominent features of the pathology.

\section{References}

1. Anker P, Stroun M, Maurice PA. Spontaneous release of DNA by human blood lymphocytes as shown in an in vitro system. Cancer Res (1975) 35(9):2375-82. Epub 1975/09/01. PubMed PMID: 1149042.

2. Rogers JC. Identification of an intracellular precursor to DNA excreted by human lymphocytes. Proc Natl Acad Sci U S A (1976) 73(9):3211-5. Epub 1976/09/01. doi: 10.1073/pnas.73.9.3211. PubMed PMID: 1067614; PubMed Central PMCID: PMCPMC430982.

3. Jachertz D, Anker P, Maurice PA, Stroun M. Information carried by the DNA released by antigen-stimulated lymphocytes. Immunology (1979) 37(4):753-63. Epub 1979/08/01. PubMed PMID: 500126; PubMed Central PMCID: PMCPMC1457141.

4. Takei H, Araki A, Watanabe H, Ichinose A, Sendo F. Rapid killing of human neutrophils by the potent activator phorbol 12-myristate 13-acetate (PMA) accompanied by changes different from typical apoptosis or necrosis. Journal of leukocyte biology (1996) 59(2):229-40. Epub 1996/02/01. doi: 10.1002/jlb.59.2.229. PubMed PMID: 8603995.

5. Brinkmann V, Reichard U, Goosman C, Fauler B, Uhlemann Y, Weiss DS, et al. Neutrophil extracellular traps kill bacteria. Science (2004) 303:1532-5.

6. Ingelsson B, Soderberg D, Strid T, Soderberg A, Bergh AC, Loitto V, et al. Lymphocytes eject interferogenic mitochondrial DNA webs in response to CpG and non-CpG oligodeoxynucleotides of class C. Proc Natl Acad Sci US A (2018) 115(3):E478E87. Epub 2018/01/04. doi: 10.1073/pnas.1711950115. PubMed PMID: 29295921; PubMed Central PMCID: PMCPMC5776968.

7. Rocha Arrieta YC, Rojas M, Vasquez G, Lopez J. The Lymphocytes Stimulation Induced DNA Release, a Phenomenon Similar to NETosis. Scandinavian journal of immunology (2017) 86(4):229-38. Epub 2017/08/15. doi: 10.1111/sji.12592. PubMed PMID: 28805301.

8. Costanza M, Poliani PL, Portararo P, Cappetti B, Musio S, Pagani F, et al. DNA threads released by activated CD4(+) T lymphocytes provide autocrine costimulation. Proc Natl Acad Sci U S A (2019) 116(18):8985-94. Epub 2019/04/17. doi: 10.1073/pnas.1822013116. PubMed PMID: 30988194; PubMed Central PMCID: PMCPMC6500139.

9. Koh CC, Wardini AB, Vieira M, Passos LSA, Martinelli PM, Neves EGA, et al. Human CD8+ T Cells Release Extracellular Traps Co-Localized With Cytotoxic Vesicles That Are Associated With Lesion Progression and Severity in Human Leishmaniasis. Frontiers in immunology (2020) 11:594581. Epub 2020/10/30. doi: 10.3389/fimmu.2020.594581. PubMed PMID: 33117407; PubMed Central PMCID: PMCPMC7578246.

10. Dworski R, Simon HU, Hoskins A, Yousefi S. Eosinophil and neutrophil extracellular DNA traps in human allergic asthmatic airways. J Allergy Clin Immunol (2011) 127(5):1260-6. Epub 2011/02/15. doi: 10.1016/j.jaci.2010.12.1103. PubMed PMID: 21315435; PubMed Central PMCID: PMCPMC3085562.

11. Aulik NA, Hellenbrand KM, Czuprynski CJ. Mannheimia haemolytica and its leukotoxin cause macrophage extracellular trap formation by bovine macrophages. Infect Immun (2012) 80(5):1923-33. Epub 2012/02/23. doi: 10.1128/IAI.06120-11. PubMed PMID: 22354029; PubMed Central PMCID: PMCPMC3347434.

12. Chow OA, von Köckritz-Blickwede M, Bright AT, Hensler ME, Zinkernagel AS, Cogen AL, et al. Statins Enhance Formation of Phagocyte Extracellular Traps. Cell host \& microbe (2010) 8(5):445-54. doi: 10.1016/j.chom.2010.10.005. 
13. Yousefi S, Morshed M, Amini P, Stojkov D, Simon D, von Gunten S, et al. Basophils exhibit antibacterial activity through extracellular trap formation. Allergy (2015) 70(9):1184-8. Epub 2015/06/05. doi: 10.1111/all.12662. PubMed PMID: 26043360.

14. Swain DK, Kushwah MS, Kaur M, Patbandha TK, Mohanty AK, Dang AK. Formation of NET, phagocytic activity, surface architecture, apoptosis and expression of toll like receptors 2 and 4 (TLR2 and TLR4) in neutrophils of mastitic cows. Veterinary research communications (2014) 38(3):209-19. Epub 2014/06/12. doi: 10.1007/s11259-014-9606-1. PubMed PMID: 24915786.

15. Gondaira S, Higuchi H, Nishi K, Iwano H, Nagahata H. Mycoplasma bovis escapes bovine neutrophil extracellular traps. Veterinary microbiology (2017) 199:68-73. Epub 2017/01/24. doi: 10.1016/j.vetmic.2016.12.022. PubMed PMID: 28110787.

16. Muñoz Caro T, Hermosilla C, Silva LM, Cortes H, Taubert A. Neutrophil extracellular traps as innate immune reaction against the emerging apicomplexan parasite Besnoitia besnoiti. PloS one (2014) 9(3):e91415. Epub 2014/03/13. doi: 10.1371/journal.pone.0091415. PubMed PMID: 24618849; PubMed Central PMCID: PMCPMC3950022.

17. Aulik NA, Hellenbrand KM, Klos H, Czuprynski CJ. Mannheimia haemolytica and its leukotoxin cause neutrophil extracellular trap formation by bovine neutrophils. Infect Immun (2010) 78(11):4454-66. Epub 2010/09/09. doi: 10.1128/iai.0084010. PubMed PMID: 20823211; PubMed Central PMCID: PMCPMC2976348.

18. Grinberg N, Elazar S, Rosenshine I, Shpigel NY. Beta-hydroxybutyrate abrogates formation of bovine neutrophil extracellular traps and bactericidal activity against mammary pathogenic Escherichia coli. Infect Immun (2008) 76(6):2802-7. Epub 2008/04/16. doi: 10.1128/iai.00051-08. PubMed PMID: 18411287; PubMed Central PMCID: PMCPMC2423099.

19. Lippolis JD, Reinhardt TA, Goff JP, Horst RL. Neutrophil extracellular trap formation by bovine neutrophils is not inhibited by milk. Veterinary immunology and immunopathology (2006) 113(1-2):248-55. Epub 2006/06/30. doi: 10.1016/j.vetimm.2006.05.004. PubMed PMID: 16806491.

20. Behrendt JH, Ruiz A, Zahner H, Taubert A, Hermosilla C. Neutrophil extracellular trap formation as innate immune reactions against the apicomplexan parasite Eimeria bovis. Veterinary immunology and immunopathology (2010) 133(1):1-8. Epub 2009/07/25. doi: 10.1016/j.vetimm.2009.06.012. PubMed PMID: 19625090.

21. Bréa D, Meurens F, Dubois AV, Gaillard J, Chevaleyre C, Jourdan ML, et al. The pig as a model for investigating the role of neutrophil serine proteases in human inflammatory lung diseases. The Biochemical journal (2012) 447(3):363-70. Epub 2012/08/07. doi: 10.1042/bj20120818. PubMed PMID: 22860995; PubMed Central PMCID: PMCPMC3492928.

22. de Buhr N, Neumann A, Jerjomiceva N, von Köckritz-Blickwede M, Baums CG. Streptococcus suis DNase SsnA contributes to degradation of neutrophil extracellular traps (NETs) and evasion of NET-mediated antimicrobial activity. Microbiology (Reading, England) (2014) 160(Pt 2):385-95. Epub 2013/11/14. doi: 10.1099/mic.0.072199-0. PubMed PMID: 24222615.

23. Loving CL, Kehrli ME, Jr., Brockmeier SL, Bayles DO, Michael DD, Schlink SN, et al. Porcine granulocyte-colony stimulating factor (G-CSF) delivered via replication-defective adenovirus induces a sustained increase in circulating peripheral blood neutrophils. Biologicals : journal of the International Association of Biological Standardization (2013) 41(6):368-76. Epub 2013/07/31. doi: 10.1016/j.biologicals.2013.07.001. PubMed PMID: 23891494.

24. Rebordão MR, Carneiro C, Alexandre-Pires G, Brito P, Pereira C, Nunes T, et al. Neutrophil extracellular traps formation by bacteria causing endometritis in the mare. Journal of reproductive immunology (2014) 106:41-9. Epub 2014/09/15. doi: 10.1016/j.jri.2014.08.003. PubMed PMID: 25218891.

25. Alghamdi AS, Foster DN. Seminal DNase frees spermatozoa entangled in neutrophil extracellular traps. Biology of reproduction (2005) 73(6):1174-81. Epub 2005/08/19. doi: 10.1095/biolreprod.105.045666. PubMed PMID: 16107606.

26. Herteman N, Vargas A, Lavoie JP. Characterization of Circulating Low-Density Neutrophils Intrinsic Properties in Healthy and Asthmatic Horses. Scientific reports (2017) 7(1):7743. Epub 2017/08/12. doi: 10.1038/s41598-017-08089-5. PubMed PMID: 28798364; PubMed Central PMCID: PMCPMC5552858.

27. Chuammitri P, Redmond SB, Kimura K, Andreasen CB, Lamont SJ, Palić D. Heterophil functional responses to dietary immunomodulators vary in genetically distinct chicken lines. Veterinary immunology and immunopathology (2011) 142(34):219-27. Epub 2011/06/08. doi: 10.1016/j.vetimm.2011.05.019. PubMed PMID: 21645931.

28. Chuammitri P, Ostojić J, Andreasen CB, Redmond SB, Lamont SJ, Palić D. Chicken heterophil extracellular traps (HETs): novel defense mechanism of chicken heterophils. Veterinary immunology and immunopathology (2009) 129(1-2):126-31. Epub 2009/01/31. doi: 10.1016/j.vetimm.2008.12.013. PubMed PMID: 19178950.

29. Palić D, Andreasen CB, Ostojić J, Tell RM, Roth JA. Zebrafish (Danio rerio) whole kidney assays to measure neutrophil extracellular trap release and degranulation of primary granules. Journal of immunological methods (2007) 319(1-2):87-97. Epub 2007/01/09. doi: 10.1016/j.jim.2006.11.003. PubMed PMID: 17208252.

30. Gratacap RL, Scherer AK, Seman BG, Wheeler RT. Control of Mucosal Candidiasis in the Zebrafish Swim Bladder Depends on Neutrophils That Block Filament Invasion and Drive Extracellular-Trap Production. Infect Immun (2017) 85(9). Epub 2017/06/14. doi: 10.1128/iai.00276-17. PubMed PMID: 28607100; PubMed Central PMCID: PMCPMC5563567.

31. Brogden G, von Köckritz-Blickwede M, Adamek M, Reuner F, Jung-Schroers V, Naim HY, et al. $\beta$-Glucan protects neutrophil extracellular traps against degradation by Aeromonas hydrophila in carp (Cyprinus carpio). Fish \& shellfish immunology (2012) 33(4):1060-4. Epub 2012/09/11. doi: 10.1016/j.fsi.2012.08.009. PubMed PMID: 22959188.

32. Pijanowski L, Golbach L, Kolaczkowska E, Scheer M, Verburg-van Kemenade BM, Chadzinska M. Carp neutrophilic granulocytes form extracellular traps via ROS-dependent and independent pathways. Fish \& shellfish immunology (2013) 34(5):1244-52. Epub 2013/02/21. doi: 10.1016/j.fsi.2013.02.010. PubMed PMID: 23422817. 
33. Chi H, Sun L. Neutrophils of Scophthalmus maximus produce extracellular traps that capture bacteria and inhibit bacterial infection. Developmental and comparative immunology (2016) 56:7-12. Epub 2015/11/21. doi: 10.1016/j.dci.2015.11.005. PubMed PMID: 26586641.

34. Zhao ML, Chi H, Sun L. Neutrophil Extracellular Traps of Cynoglossus semilaevis: Production Characteristics and Antibacterial Effect. Frontiers in immunology (2017) 8:290. Epub 2017/04/07. doi: 10.3389/fimmu.2017.00290. PubMed PMID: 28382034; PubMed Central PMCID: PMCPMC5360709.

35. Robb CT, Dyrynda EA, Gray RD, Rossi AG, Smith VJ. Invertebrate extracellular phagocyte traps show that chromatin is an ancient defence weapon. Nature communications (2014) 5:4627. Epub 2014/08/15. doi: 10.1038/ncomms5627. PubMed PMID: 25115909; PubMed Central PMCID: PMCPMC4143918.

36. $\mathrm{Ng} \mathrm{TH}$, Chang SH, Wu MH, Wang HC. Shrimp hemocytes release extracellular traps that kill bacteria. Developmental and comparative immunology (2013) 41(4):644-51. Epub 2013/07/03. doi: 10.1016/j.dci.2013.06.014. PubMed PMID: 23817142.

37. $\mathrm{Ng} \mathrm{TH}, \mathrm{Wu} \mathrm{MH}$, Chang SH, Aoki T, Wang HC. The DNA fibers of shrimp hemocyte extracellular traps are essential for the clearance of Escherichia coli. Developmental and comparative immunology (2015) 48(1):229-33. Epub 2014/12/03. doi: 10.1016/j.dci.2014.10.011. PubMed PMID: 25450908.

38. Lange MK, Penagos-Tabares F, Muñoz-Caro T, Gärtner U, Mejer H, Schaper R, et al. Gastropod-derived haemocyte extracellular traps entrap metastrongyloid larval stages of Angiostrongylus vasorum, Aelurostrongylus abstrusus and Troglostrongylus brevior. Parasites \& vectors (2017) 10(1):50. Epub 2017/02/02. doi: 10.1186/s13071-016-1961-z. PubMed PMID: 28143510; PubMed Central PMCID: PMCPMC5282800.

39. Poirier AC, Schmitt P, Rosa RD, Vanhove AS, Kieffer-Jaquinod S, Rubio TP, et al. Antimicrobial histones and DNA traps in invertebrate immunity: evidences in Crassostrea gigas. The Journal of Biological Chemistry (2014) 289(36):24821-31. Epub 2014/07/20. doi: 10.1074/jbc.M114.576546. PubMed PMID: 25037219; PubMed Central PMCID: PMCPMC4155652.

40. Wen F, White GJ, VanEtten HD, Xiong Z, Hawes MC. Extracellular DNA is required for root tip resistance to fungal infection. Plant physiology (2009) 151(2):820-9. Epub 2009/08/25. doi: 10.1104/pp.109.142067. PubMed PMID: 19700564; PubMed Central PMCID: PMCPMC2754639.

41. Tran TM, MacIntyre A, Hawes M, Allen C. Escaping Underground Nets: Extracellular DNases Degrade Plant Extracellular Traps and Contribute to Virulence of the Plant Pathogenic Bacterium Ralstonia solanacearum. PLoS pathogens (2016) 12(6):e1005686. Epub 2016/06/24. doi: 10.1371/journal.ppat.1005686. PubMed PMID: 27336156; PubMed Central PMCID: PMCPMC4919084.

42. Ramos-Martínez E, Hernández-González L, Ramos-Martínez I, Pérez-Campos Mayoral L, López-Cortés GI, Pérez-Campos E, et al. Multiple Origins of Extracellular DNA Traps. Frontiers in immunology (2021) 12:621311-. doi: 10.3389/fimmu.2021.621311. PubMed PMID: 33717121.

43. Buchanan JT, Simpson AJ, Aziz RK, Liu GY, Kristian SA, Kotb M, et al. DNase expression allows the pathogen group A Streptococcus to escape killing in neutrophil extracellular traps. Current biology : CB (2006) 16(4):396-400. Epub 2006/02/21. doi: 10.1016/j.cub.2005.12.039. PubMed PMID: 16488874.

44. Beiter K, Wartha F, Albiger B, Normark S, Zychlinsky A, Henriques-Normark B. An endonuclease allows Streptococcus pneumoniae to escape from neutrophil extracellular traps. Current biology : CB (2006) 16(4):401-7. Epub 2006/02/21. doi: 10.1016/j.cub.2006.01.056. PubMed PMID: 16488875.

45. Walker MJ, Hollands A, Sanderson-Smith ML, Cole JN, Kirk JK, Henningham A, et al. DNase Sda1 provides selection pressure for a switch to invasive group A streptococcal infection. Nature medicine (2007) 13(8):981-5. Epub 2007/07/17. doi: 10.1038/nm1612. PubMed PMID: 17632528.

46. Tonello S, Rizzi M, Migliario M, Rocchetti V, Renò F. Low concentrations of neutrophil extracellular traps induce proliferation in human keratinocytes via NF-kB activation. Journal of dermatological science (2017) 88(1):110-6. Epub 2017/06/04. doi: 10.1016/j.jdermsci.2017.05.010. PubMed PMID: 28576417.

47. Hofbauer TM, Mangold A, Scherz T, Seidl V, Panzenböck A, Ondracek AS, et al. Neutrophil extracellular traps and fibrocytes in ST-segment elevation myocardial infarction. Basic research in cardiology (2019) 114(5):33. Epub 2019/07/18. doi: 10.1007/s00395-019-0740-3. PubMed PMID: 31312919; PubMed Central PMCID: PMCPMC6647191.

48. Arampatzioglou A, Papazoglou D, Konstantinidis T, Chrysanthopoulou A, Mitsios A, Angelidou I, et al. Clarithromycin Enhances the Antibacterial Activity and Wound Healing Capacity in Type 2 Diabetes Mellitus by Increasing LL-37 Load on Neutrophil Extracellular Traps. Frontiers in immunology (2018) 9:2064. Epub 2018/09/27. doi: 10.3389/fimmu.2018.02064. PubMed PMID: 30250474; PubMed Central PMCID: PMCPMC6139320.

49. Wong SL, Demers M, Martinod K, Gallant M, Wang Y, Goldfine AB, et al. Diabetes primes neutrophils to undergo NETosis, which impairs wound healing. Nat Med (2015) 21(7):815-9. Epub 2015/06/16. doi: 10.1038/nm.3887. PubMed PMID: 26076037; PubMed Central PMCID: PMCPMC4631120.

50. Njeim R, Azar WS, Fares AH, Azar ST, Kfoury Kassouf H, Eid AA. NETosis contributes to the pathogenesis of diabetes and its complications. Journal of molecular endocrinology (2020) 65(4):R65-r76. Epub 2020/10/14. doi: 10.1530/jme-20-0128. PubMed PMID: 33048064.

51. Fadini GP, Menegazzo L, Rigato M, Scattolini V, Poncina N, Bruttocao A, et al. NETosis Delays Diabetic Wound Healing in Mice and Humans. Diabetes (2016) 65(4):1061-71. Epub 2016/01/08. doi: 10.2337/db15-0863. PubMed PMID: 26740598.

52. Bitschar K, Staudenmaier L, Klink L, Focken J, Sauer B, Fehrenbacher B, et al. Staphylococcus aureus Skin Colonization Is Enhanced by the Interaction of Neutrophil Extracellular Traps with Keratinocytes. The Journal of investigative dermatology (2020) 140(5):1054-65.e4. Epub 2019/12/21. doi: 10.1016/j.jid.2019.10.017. PubMed PMID: 31857094. 
53. Neeli I, Khan SN, Radic M. Histone deimination as a response to inflammatory stimuli in neutrophils. J Immunol (2008) 180(3):1895-902. Epub 2008/01/23. doi: 10.4049/jimmunol.180.3.1895. PubMed PMID: 18209087.

54. 54.Wang Y, Li M, Stadler S, Correll S, Li P, Wang D, et al. Histone hypercitrullination mediates chromatin decondensation and neutrophil extracellular trap formation. The Journal of cell biology (2009) 184(2):205-13. Epub 2009/01/21. doi: 10.1083/jcb.200806072. PubMed PMID: 19153223; PubMed Central PMCID: PMCPMC2654299.

55. 55.Li P, Li M, Lindberg MR, Kennett MJ, Xiong N, Wang Y. PAD4 is essential for antibacterial innate immunity mediated by neutrophil extracellular traps. Journal of Experimental Medicine (2010) 207(9):1853-62. doi: 10.1084/jem.20100239.

56. 56.Fuchs TA, Abed U, Goosmann C, Hurwitz R, Schulze I, Wahn V, et al. Novel cell death program leads to neutrophil extracellular traps. J Cell Biol (2007) 176(2):231-41. Epub 2007/01/11. doi: 10.1083/jcb.200606027. PubMed PMID: 17210947; PubMed Central PMCID: PMCPMC2063942.

57. 57.Remijsen Q, Vanden Berghe T, Wirawan E, Asselbergh B, Parthoens E, De Rycke R, et al. Neutrophil extracellular trap cell death requires both autophagy and superoxide generation. Cell research (2011) 21(2):290-304. Epub 2010/11/10. doi: 10.1038/cr.2010.150. PubMed PMID: 21060338; PubMed Central PMCID: PMCPMC3193439.

58. 58.Kenny EF, Herzig A, Krüger R, Muth A, Mondal S, Thompson PR, et al. Diverse stimuli engage different neutrophil extracellular trap pathways. eLife (2017) 6. Epub 2017/06/03. doi: 10.7554/eLife.24437. PubMed PMID: 28574339; PubMed Central PMCID: PMCPMC5496738.

59. 59.Sollberger G, Choidas A, Burn GL, Habenberger P, Di Lucrezia R, Kordes S, et al. Gasdermin D plays a vital role in the generation of neutrophil extracellular traps. Sci Immunol (2018) 3(26). Epub 2018/08/26. doi: 10.1126/sciimmunol.aar6689. PubMed PMID: 30143555.

60. 60.Desai J, Kumar SV, Mulay SR, Konrad L, Romoli S, Schauer C, et al. PMA and crystal-induced neutrophil extracellular trap formation involves RIPK1-RIPK3-MLKL signaling. Eur J Immunol (2016) 46(1):223-9. Epub 2015/11/05. doi: 10.1002/eji.201545605. PubMed PMID: 26531064.

61. 61.Desai J, Foresto-Neto O, Honarpisheh M, Steiger S, Nakazawa D, Popper B, et al. Particles of different sizes and shapes induce neutrophil necroptosis followed by the release of neutrophil extracellular trap-like chromatin. Scientific reports (2017) 7(1):15003. Epub 2017/11/05. doi: 10.1038/s41598-017-15106-0. PubMed PMID: 29101355; PubMed Central PMCID: PMCPMC5670218.

62. 62. Nakazawa D, Desai J, Steiger S, Müller S, Devarapu SK, Mulay SR, et al. Activated platelets induce MLKL-driven neutrophil necroptosis and release of neutrophil extracellular traps in venous thrombosis. Cell death discovery (2018) 4:6. Epub 2018/08/01. doi: 10.1038/s41420-018-0073-2. PubMed PMID: 30062055; PubMed Central PMCID: PMCPMC6060161.

63. 63.Schreiber A, Rousselle A, Becker JU, von Massenhausen A, Linkermann A, Kettritz R. Necroptosis controls NET generation and mediates complement activation, endothelial damage, and autoimmune vasculitis. Proc Natl Acad Sci U S A (2017) 114(45):E9618-E25. Epub 2017/10/29. doi: 10.1073/pnas.1708247114. PubMed PMID: 29078325; PubMed Central PMCID: PMCPMC5692554.

64. 64. Amini P, Stojkov D, Wang X, Wicki S, Kaufmann T, Wong WW, et al. NET formation can occur independently of RIPK3 and MLKL signaling. Eur J Immunol (2016) 46(1):178-84. Epub 2015/11/10. doi: 10.1002/eji.201545615. PubMed PMID: 26549703; PubMed Central PMCID: PMCPMC4738457.

65. 65.Pieterse E, Rother N, Yanginlar C, Hilbrands LB, van der Vlag J. Neutrophils Discriminate between Lipopolysaccharides of Different Bacterial Sources and Selectively Release Neutrophil Extracellular Traps. Frontiers in immunology (2016) 7:484. Epub 2016/11/22. doi: 10.3389/fimmu.2016.00484. PubMed PMID: 27867387; PubMed Central PMCID: PMCPMC5095130.

66. 66. Yipp BG, Petri B, Salina D, Jenne CN, Scott BNV, Zbytnuik LD, et al. Infection-induced NETosis is a dynamic process involving neutrophil multitasking in vivo. Nature medicine (2012) 18(9):1386-93. doi: 10.1038/nm.2847. PubMed PMID: 22922410.

67. 67.Pilsczek FH, Salina D, Poon KKH, Fahey C, Yipp BG, Sibley CD, et al. A Novel Mechanism of Rapid Nuclear Neutrophil Extracellular Trap Formation in Response to Staphylococcus aureus. The Journal of Immunology (2010) 185(12):7413-25. doi: 10.4049/jimmunol.1000675.

68. 68.Clark SR, Ma AC, Tavener SA, McDonald B, Goodarzi Z, Kelly MM, et al. Platelet TLR4 activates neutrophil extracellular traps to ensnare bacteria in septic blood. Nature medicine (2007) 13(4):463-9. Epub 2007/03/27. doi: 10.1038/nm1565. PubMed PMID: 17384648.

69. 69.Berends ET, Horswill AR, Haste NM, Monestier M, Nizet V, von Köckritz-Blickwede M. Nuclease expression by Staphylococcus aureus facilitates escape from neutrophil extracellular traps. Journal of innate immunity (2010) 2(6):576-86. Epub 2010/09/11. doi: 10.1159/000319909. PubMed PMID: 20829609; PubMed Central PMCID: PMCPMC2982853.

70. 70.Sumby P, Barbian KD, Gardner DJ, Whitney AR, Welty DM, Long RD, et al. Extracellular deoxyribonuclease made by group A Streptococcus assists pathogenesis by enhancing evasion of the innate immune response. Proc Natl Acad Sci U S A (2005) 102(5):1679-84. Epub 2005/01/26. doi: 10.1073/pnas.0406641102. PubMed PMID: 15668390; PubMed Central PMCID: PMCPMC547841.

71. 71.Yousefi S, Mihalache C, Kozlowski E, Schmid I, Simon HU. Viable neutrophils release mitochondrial DNA to form neutrophil extracellular traps. Cell Death Differ (2009) 16(11):1438-44. Epub 2009/07/18. doi: 10.1038/cdd.2009.96. PubMed PMID: 19609275.

72. 72.Lood C, Blanco LP, Purmalek MM, Carmona-Rivera C, De Ravin SS, Smith CK, et al. Neutrophil extracellular traps enriched in oxidized mitochondrial DNA are interferogenic and contribute to lupus-like disease. Nat Med (2016) 22(2):14653. Epub 2016/01/19. doi: 10.1038/nm.4027. PubMed PMID: 26779811; PubMed Central PMCID: PMCPMC4742415. 
73. 73. McIlroy DJ, Jarnicki AG, Au GG, Lott N, Smith DW, Hansbro PM, et al. Mitochondrial DNA neutrophil extracellular traps are formed after trauma and subsequent surgery. Journal of Critical Care (2014) 29(6):1133.e1-.e5. doi: https://doi.org/10.1016/j.jcrc.2014.07.013.

74. 74.Itagaki K, Kaczmarek E, Lee YT, Tang IT, Isal B, Adibnia Y, et al. Mitochondrial DNA Released by Trauma Induces Neutrophil Extracellular Traps. PloS one (2015) 10(3):e0120549. doi: 10.1371/journal.pone.0120549.

75. 75. Arai Y, Nishinaka Y, Arai T, Morita M, Mizugishi K, Adachi S, et al. Uric acid induces NADPH oxidase-independent neutrophil extracellular trap formation. Biochemical and biophysical research communications (2014) 443(2):556-61. Epub 2013/12/12. doi: 10.1016/j.bbrc.2013.12.007. PubMed PMID: 24326071.

76. 76.Saitoh T, Komano J, Saitoh Y, Misawa T, Takahama M, Kozaki T, et al. Neutrophil Extracellular Traps Mediate a Host Defense Response to Human Immunodeficiency Virus-1. Cell host \& microbe (2012) 12(1):109-16. doi: 10.1016/j.chom.2012.05.015.

77. 77.Funchal GA, Jaeger N, Czepielewski RS, Machado MS, Muraro SP, Stein RT, et al. Respiratory Syncytial Virus Fusion Protein Promotes TLR-4-Dependent Neutrophil Extracellular Trap Formation by Human Neutrophils. PloS one (2015) 10(4):e0124082. doi: 10.1371/journal.pone.0124082.

78. 78. Hiroki CH, Toller-Kawahisa JE, Fumagalli MJ, Colon DF, Figueiredo LTM, Fonseca BALD, et al. Neutrophil Extracellular Traps Effectively Control Acute Chikungunya Virus Infection. Frontiers in immunology (2020) 10. doi: 10.3389/fimmu.2019.03108.

79. 79.Wolfson M, McPhail LC, Nasrallah VN, Snyderman R. Phorbol myristate acetate mediates redistribution of protein kinase $C$ in human neutrophils: potential role in the activation of the respiratory burst enzyme. Journal of immunology (Baltimore, Md : 1950) (1985) 135(3):2057-62. Epub 1985/09/01. PubMed PMID: 3160785.

80. 80.Hakkim A, Fuchs TA, Martinez NE, Hess S, Prinz H, Zychlinsky A, et al. Activation of the Raf-MEK-ERK pathway is required for neutrophil extracellular trap formation. Nat Chem Biol (2011) 7(2):75-7. Epub 2010/12/21. doi: 10.1038/nchembio.496. PubMed PMID: 21170021.

81. 81.Ermert D, Zychlinsky A, Urban C. Fungal and bacterial killing by neutrophils. Methods in molecular biology (Clifton, NJ) (2009) 470:293-312. Epub 2008/12/18. doi: 10.1007/978-1-59745-204-5_21. PubMed PMID: 19089391.

82. 82. Metzler KD, Fuchs TA, Nauseef WM, Reumaux D, Roesler J, Schulze I, et al. Myeloperoxidase is required for neutrophil extracellular trap formation: implications for innate immunity. Blood (2011) 117(3):953-9. Epub 2010/10/27. doi: 10.1182/blood-2010-06-290171. PubMed PMID: 20974672; PubMed Central PMCID: PMCPMC3035083.

83. 83.Papayannopoulos V, Metzler KD, Hakkim A, Zychlinsky A. Neutrophil elastase and myeloperoxidase regulate the formation of neutrophil extracellular traps. The Journal of cell biology (2010) 191(3):677-91. Epub 2010/10/27. doi: 10.1083/jcb.201006052. PubMed PMID: 20974816; PubMed Central PMCID: PMCPMC3003309.

84. 84. Metzler KD, Goosmann C, Lubojemska A, Zychlinsky A, Papayannopoulos V. A myeloperoxidase-containing complex regulates neutrophil elastase release and actin dynamics during NETosis. Cell Rep (2014) 8(3):883-96. Epub 2014/07/30. doi: 10.1016/j.celrep.2014.06.044. PubMed PMID: 25066128; PubMed Central PMCID: PMCPMC4471680.

85. 85.Dömer D, Walther T, Möller S, Behnen M, Laskay T. Neutrophil Extracellular Traps Activate Proinflammatory Functions of Human Neutrophils. Frontiers in immunology (2021) 12. doi: 10.3389/fimmu.2021.636954.

86. 86. Ribon M, Seninet S, Mussard J, Sebbag M, Clavel C, Serre G, et al. Neutrophil extracellular traps exert both pro- and anti-inflammatory actions in rheumatoid arthritis that are modulated by C1q and LL-37. Journal of Autoimmunity (2019) 98:122-31. doi: https://doi.org/10.1016/j.jaut.2019.01.003.

87. 87. Ospina FE, Betancur JF, Suso JP, Muñoz-Buitrón E, Cañas CA, Tobón GJ. Role of the cytokine BAFF in autoimmune diseases: physiopathology and therapeutic targets. Revista Colombiana de Reumatología (2016) 23:177-94.

88. 88. Chen KW, Monteleone M, Boucher D, Sollberger G, Ramnath D, Condon ND, et al. Noncanonical inflammasome signaling elicits gasdermin D-dependent neutrophil extracellular traps. Sci Immunol (2018) 3(26). Epub 2018/08/26. doi: 10.1126/sciimmunol.aar6676. PubMed PMID: 30143554.

89. 89. Homa-Mlak I, Majdan A, Mlak R, Małecka-Massalska T. Metastatic potential of NET in neoplastic disease. Postepy higieny i medycyny doswiadczalnej (Online) (2016) 70(0):887-95. Epub 2016/09/07. doi: 10.5604/17322693.1216275. PubMed PMID: 27594564.

90. 90. Oklu R, Sheth RA, Wong KHK, Jahromi AH, Albadawi H. Neutrophil extracellular traps are increased in cancer patients but does not associate with venous thrombosis. Cardiovascular diagnosis and therapy (2017) 7(Suppl 3):S140-s9. Epub 2018/02/06. doi: 10.21037/cdt.2017.08.01. PubMed PMID: 29399517; PubMed Central PMCID: PMCPMC5778521.

91. 91.Li Y, Yang Y, Gan T, Zhou J, Hu F, Hao N, et al. Extracellular RNAs from lung cancer cells activate epithelial cells and induce neutrophil extracellular traps. International journal of oncology (2019) 55(1):69-80. Epub 2019/05/23. doi: 10.3892/ijo.2019.4808. PubMed PMID: 31115506; PubMed Central PMCID: PMCPMC6561626.

92. 92.Saffarzadeh M, Juenemann C, Queisser MA, Lochnit G, Barreto G, Galuska SP, et al. Neutrophil extracellular traps directly induce epithelial and endothelial cell death: a predominant role of histones. PloS one (2012) 7(2):e32366. Epub 2012/03/06. doi: 10.1371/journal.pone.0032366. PubMed PMID: 22389696; PubMed Central PMCID: PMCPMC3289648.

93. 93.Cedervall J, Hamidi A, Olsson AK. Platelets, NETs and cancer. Thrombosis research (2018) 164 Suppl 1:S148-s52. Epub 2018/04/29. doi: 10.1016/j.thromres.2018.01.049. PubMed PMID: 29703474.

94. 94.Schedel F, Mayer-Hain S, Pappelbaum KI, Metze D, Stock M, Goerge T, et al. Evidence and impact of neutrophil extracellular traps in malignant melanoma. Pigment cell \& melanoma research (2020) 33(1):63-73. Epub 2019/08/14. doi: 10.1111/pcmr.12818. PubMed PMID: 31402559. 
95. 95.Najmeh S, Cools-Lartigue J, Rayes RF, Gowing S, Vourtzoumis P, Bourdeau F, et al. Neutrophil extracellular traps sequester circulating tumor cells via $\beta 1$-integrin mediated interactions. International journal of cancer (2017) 140(10):2321-30. Epub 2017/02/09. doi: 10.1002/ijc.30635. PubMed PMID: 28177522.

96. 96. Masucci MT, Minopoli M, Del Vecchio S, Carriero MV. The Emerging Role of Neutrophil Extracellular Traps (NETs) in Tumor Progression and Metastasis. Frontiers in immunology (2020) 11. doi: 10.3389/fimmu.2020.01749.

97. 97. Yang L, Liu Q, Zhang X, Liu X, Zhou B, Chen J, et al. DNA of neutrophil extracellular traps promotes cancer metastasis via CCDC25. Nature (2020) 583(7814):133-8. doi: 10.1038/s41586-020-2394-6.

98. 98.Zhu T, Zou X, Yang C, Li L, Wang B, Li R, et al. Neutrophil extracellular traps promote gastric cancer metastasis by inducing epithelial-mesenchymal transition. Int J Mol Med (2021) 48(1):127. doi: 10.3892/ijmm.2021.4960.

99. 99. Yazdani HO, Roy E, Comerci AJ, van der Windt DJ, Zhang H, Huang H, et al. Neutrophil Extracellular Traps Drive Mitochondrial Homeostasis in Tumors to Augment Growth. Cancer Res (2019) 79(21):5626-39. Epub 2019/09/15. doi: 10.1158/0008-5472.Can-19-0800. PubMed PMID: 31519688; PubMed Central PMCID: PMCPMC6825588.

100. 100. Moscarello MA, Wood DD, Ackerley C, Boulias C. Myelin in multiple sclerosis is developmentally immature. The Journal of clinical investigation (1994) 94(1):146-54. Epub 1994/07/01. doi: 10.1172/jci117300. PubMed PMID: 7518827; PubMed Central PMCID: PMCPMC296292.

101. 101. Pritzker LB, Joshi S, Gowan JJ, Harauz G, Moscarello MA. Deimination of myelin basic protein. 1. Effect of deimination of arginyl residues of myelin basic protein on its structure and susceptibility to digestion by cathepsin D. Biochemistry (2000) 39(18):5374-81. Epub 2000/05/23. doi: 10.1021/bi9925569. PubMed PMID: 10820008.

102. 102. Boggs JM, Rangaraj G, Koshy KM, Ackerley C, Wood DD, Moscarello MA. Highly deiminated isoform of myelin basic protein from multiple sclerosis brain causes fragmentation of lipid vesicles. Journal of neuroscience research (1999) 57(4):529-35. Epub 1999/08/10. PubMed PMID: 10440902.

103. 103. Harauz G, Musse AA. A Tale of Two Citrullines-Structural and Functional Aspects of Myelin Basic Protein Deimination in Health and Disease. Neurochemical Research (2007) 32(2):137-58. doi: 10.1007/s11064-006-9108-9.

104. 104. Opdenakker G, Proost P, Van Damme J. Microbiomic and Posttranslational Modifications as Preludes to Autoimmune Diseases. Trends in molecular medicine (2016) 22(9):746-57. Epub 2016/08/06. doi: 10.1016/j.molmed.2016.07.002. PubMed PMID: 27491925.

105. 105. Caprariello AV, Rogers JA, Morgan ML, Hoghooghi V, Plemel JR, Koebel A, et al. Biochemically altered myelin triggers autoimmune demyelination. Proc Natl Acad Sci U S A (2018) 115(21):5528-33. Epub 2018/05/08. doi: 10.1073/pnas.1721115115. PubMed PMID: 29728463; PubMed Central PMCID: PMCPMC6003499.

106. 106. Mastronardi FG, Wood DD, Mei J, Raijmakers R, Tseveleki V, Dosch H-M, et al. Increased citrullination of histone $\mathrm{H} 3$ in multiple sclerosis brain and animal models of demyelination: a role for tumor necrosis factor-induced peptidylarginine deiminase 4 translocation. J Neurosci (2006) 26(44):11387-96. doi: 10.1523/JNEUROSCI.3349-06.2006. PubMed PMID: 17079667.

107. 107. Naegele M, Tillack K, Reinhardt S, Schippling S, Martin R, Sospedra M. Neutrophils in multiple sclerosis are characterized by a primed phenotype. Journal of neuroimmunology (2012) 242(1):60-71. doi: 10.1016/j.jneuroim.2011.11.009.

108. 108. Rumble JM, Huber AK, Krishnamoorthy G, Srinivasan A, Giles DA, Zhang X, et al. Neutrophil-related factors as biomarkers in EAE and MS. Journal of Experimental Medicine (2015) 212(1):23-35. doi: 10.1084/jem.20141015.

109. 109. Tillack K, Naegele M, Haueis C, Schippling S, Wandinger KP, Martin R, et al. Gender differences in circulating levels of neutrophil extracellular traps in serum of multiple sclerosis patients. Journal of neuroimmunology (2013) 261(12):108-19. Epub 2013/06/06. doi: 10.1016/j.jneuroim.2013.05.004. PubMed PMID: 23735283.

110. 110. Paryzhak S, Dumych T, Mahorivska I, Boichuk M, Bila G, Peshkova S, et al. Neutrophil-released enzymes can influence composition of circulating immune complexes in multiple sclerosis. Autoimmunity (2018) 51(6):297-303. doi: 10.1080/08916934.2018.1514390.

111. 111. Zhang H, Ray A, Miller NM, Hartwig D, Pritchard KA, Dittel BN. Inhibition of myeloperoxidase at the peak of experimental autoimmune encephalomyelitis restores blood-brain barrier integrity and ameliorates disease severity. Journal of neurochemistry (2016) 136(4):826-36. Epub 2015/11/13. doi: 10.1111/jnc.13426. PubMed PMID: 26560636; PubMed Central PMCID: PMCPMC4865458.

112. 112. Yu G, Zheng S, Zhang H. Inhibition of myeloperoxidase by N-acetyl lysyltyrosylcysteine amide reduces experimental autoimmune encephalomyelitis-induced injury and promotes oligodendrocyte regeneration and neurogenesis in a murine model of progressive multiple sclerosis. NeuroReport (2018) 29(3).

113. 113. Lee SA, Noel S, Sadasivam M, Hamad ARA, Rabb H. Role of Immune Cells in Acute Kidney Injury and Repair. Nephron (2017) 137(4):282-6. Epub 2017/06/12. doi: 10.1159/000477181. PubMed PMID: 28601878; PubMed Central PMCID: PMCPMC5723562.

114. 114. Bolisetty S, Agarwal A. Neutrophils in acute kidney injury: not neutral any more. Kidney international (2009) 75(7):674-6. Epub 2009/03/14. doi: 10.1038/ki.2008.689. PubMed PMID: 19282858.

115. 115. Bonavia A, Singbartl K. A review of the role of immune cells in acute kidney injury. Pediatric nephrology (Berlin, Germany) (2018) 33(10):1629-39. Epub 2017/08/13. doi: 10.1007/s00467-017-3774-5. PubMed PMID: 28801723.

116. 116. Tecklenborg J, Clayton D, Siebert S, Coley SM. The role of the immune system in kidney disease. Clinical and experimental immunology (2018) 192(2):142-50. Epub 2018/02/18. doi: 10.1111/cei.13119. PubMed PMID: 29453850; PubMed Central PMCID: PMCPMC5904695. 
117. 117. Mulay SR, Linkermann A, Anders HJ. Necroinflammation in Kidney Disease. Journal of the American Society of Nephrology : JASN (2016) 27(1):27-39. Epub 2015/09/04. doi: 10.1681/asn.2015040405. PubMed PMID: 26334031; PubMed Central PMCID: PMCPMC4696588.

118. 118. Nakazawa D, Kumar SV, Marschner J, Desai J, Holderied A, Rath L, et al. Histones and Neutrophil Extracellular Traps Enhance Tubular Necrosis and Remote Organ Injury in Ischemic AKI. Journal of the American Society of Nephrology : JASN (2017) 28(6):1753-68. Epub 2017/01/12. doi: 10.1681/asn.2016080925. PubMed PMID: 28073931; PubMed Central PMCID: PMCPMC5461800.

119. 119. Kumar SVR, Kulkarni OP, Mulay SR, Darisipudi MN, Romoli S, Thomasova D, et al. Neutrophil Extracellular Trap-Related Extracellular Histones Cause Vascular Necrosis in Severe GN. Journal of the American Society of Nephrology (2015) 26(10):2399-413. doi: 10.1681/asn.2014070673.

120. 120. Nawroth P, Handley D, Matsueda G, De Waal R, Gerlach H, Blohm D, et al. Tumor necrosis factor/cachectininduced intravascular fibrin formation in meth A fibrosarcomas. The Journal of Experimental Medicine (1988) 168(2):63747. Epub 1988/08/01. doi: 10.1084/jem.168.2.637. PubMed PMID: 3411290; PubMed Central PMCID: PMCPMC2188993.

121. 121. Hertig A, Rondeau E. Role of the Coagulation/Fibrinolysis System in Fibrin-Associated Glomerular Injury. Journal of the American Society of Nephrology (2004) 15(4):844-53. doi: 10.1097/01.Asn.0000115400.52705.83.

122. 122. Engelmann B, Massberg S. Thrombosis as an intravascular effector of innate immunity. Nat Rev Immunol (2013) 13(1):34-45. Epub 2012/12/12. doi: 10.1038/nri3345. PubMed PMID: 23222502.

123. 123. Mistry P, Kaplan MJ. Cell death in the pathogenesis of systemic lupus erythematosus and lupus nephritis. Clinical immunology (Orlando, Fla) (2017) 185:59-73. Epub 2016/10/25. doi: 10.1016/j.clim.2016.08.010. PubMed PMID: 27519955; PubMed Central PMCID: PMCPMC5299061.

124. 124. Kanjanabuch T, Kittikowit W, Eiam-Ong S. An update on acute postinfectious glomerulonephritis worldwide. Nature reviews Nephrology (2009) 5(5):259-69. Epub 2009/04/23. doi: 10.1038/nrneph.2009.44. PubMed PMID: 19384327.

125. 125. Tesar V, Hruskova Z. Treatment of proliferative lupus nephritis: a slowly changing landscape. Nature reviews Nephrology (2011) 7(2):96-109. Epub 2010/12/22. doi: 10.1038/nrneph.2010.170. PubMed PMID: 21173789.

126. 126. Menzi CP, Bucher BS, Bianchetti MG, Ardissino G, Simonetti GD. Management and outcomes of childhood Goodpasture's disease. Pediatric research (2018) 83(4):813-7. Epub 2017/12/16. doi: 10.1038/pr.2017.315. PubMed PMID: 29244791.

127. 127. Hopfner K-P, Hornung V. Molecular mechanisms and cellular functions of cGAS-STING signalling. Nature Reviews Molecular Cell Biology (2020) 21(9):501-21. doi: 10.1038/s41580-020-0244-x.

128. 128. Villanueva E, Yalavarthi S, Berthier CC, Hodgin JB, Khandpur R, Lin AM, et al. Netting neutrophils induce endothelial damage, infiltrate tissues, and expose immunostimulatory molecules in systemic lupus erythematosus. Journal of immunology (Baltimore, Md : 1950) (2011) 187(1):538-52. Epub 2011/05/27. doi: 10.4049/jimmunol.1100450. PubMed PMID: 21613614; PubMed Central PMCID: PMCPMC3119769.

129. 129. Rother N, Pieterse E, Lubbers J, Hilbrands L, van der Vlag J. Acetylated Histones in Apoptotic Microparticles Drive the Formation of Neutrophil Extracellular Traps in Active Lupus Nephritis. Frontiers in immunology (2017) 8:1136. Epub 2017/09/30. doi: 10.3389/fimmu.2017.01136. PubMed PMID: 28959262; PubMed Central PMCID: PMCPMC5604071.

130. 130. Zhang S, Lu X, Shu X, Tian X, Yang H, Yang W, et al. Elevated plasma cfDNA may be associated with active lupus nephritis and partially attributed to abnormal regulation of neutrophil extracellular traps (NETs) in patients with systemic lupus erythematosus. Internal medicine (Tokyo, Japan) (2014) 53(24):2763-71. Epub 2014/12/17. doi: 10.2169/internalmedicine.53.2570. PubMed PMID: 25500436.

131. 131. Hakkim A, Fürnrohr BG, Amann K, Laube B, Abed UA, Brinkmann V, et al. Impairment of neutrophil extracellular trap degradation is associated with lupus nephritis. Proc Natl Acad Sci U S A (2010) 107(21):9813-8. Epub 2010/05/05. doi: 10.1073/pnas.0909927107. PubMed PMID: 20439745; PubMed Central PMCID: PMCPMC2906830.

132. 132. Kallenberg CG. Pathogenesis of ANCA-associated vasculitides. Annals of the rheumatic diseases (2011) 70 Suppl 1:i59-63. Epub 2011/02/26. doi: 10.1136/ard.2010.138024. PubMed PMID: 21339221.

133. 133. O'Sullivan KM, Lo CY, Summers SA, Elgass KD, McMillan PJ, Longano A, et al. Renal participation of myeloperoxidase in antineutrophil cytoplasmic antibody (ANCA)-associated glomerulonephritis. Kidney Int (2015) 88(5):1030-46. Epub 2015/07/16. doi: 10.1038/ki.2015.202. PubMed PMID: 26176828.

134. 134. Kitching AR, Anders HJ, Basu N, Brouwer E, Gordon J, Jayne DR, et al. ANCA-associated vasculitis. Nature reviews Disease primers (2020) 6(1):71. Epub 2020/08/29. doi: 10.1038/s41572-020-0204-y. PubMed PMID: 32855422.

135. 135. Radford DJ, Savage CO, Nash GB. Treatment of rolling neutrophils with antineutrophil cytoplasmic antibodies causes conversion to firm integrin-mediated adhesion. Arthritis and rheumatism (2000) 43(6):1337-45. Epub 2000/06/17. doi: 10.1002/1529-0131(200006)43:6<1337::Aid-anr16>3.0.Co;2-m. PubMed PMID: 10857792.

136. 136. Xiao H, Schreiber A, Heeringa P, Falk RJ, Jennette JC. Alternative complement pathway in the pathogenesis of disease mediated by anti-neutrophil cytoplasmic autoantibodies. Am J Pathol (2007) 170(1):52-64. Epub 2007/01/04. doi: 10.2353/ajpath.2007.060573. PubMed PMID: 17200182; PubMed Central PMCID: PMCPMC1762697.

137. 137. Yoshida M, Yamada M, Sudo Y, Kojima T, Tomiyasu T, Yoshikawa N, et al. Myeloperoxidase anti-neutrophil cytoplasmic antibody affinity is associated with the formation of neutrophil extracellular traps in the kidney and vasculitis activity in myeloperoxidase anti-neutrophil cytoplasmic antibody-associated microscopic polyangiitis. Nephrology (Carlton, Vic) (2016) 21(7):624-9. Epub 2016/02/03. doi: 10.1111/nep.12736. PubMed PMID: 26833773; PubMed Central PMCID: PMCPMC5129529. 
138. 138. Gadola SD, Gross WL. Vasculitis in 2011: the renaissance of granulomatous inflammation in AAV. Nature reviews Rheumatology (2012) 8(2):74-6. Epub 2012/01/11. doi: 10.1038/nrrheum.2011.218. PubMed PMID: 22231230.

139. 139. Nakazawa D, Shida H, Tomaru U, Yoshida M, Nishio S, Atsumi T, et al. Enhanced formation and disordered regulation of NETs in myeloperoxidase-ANCA-associated microscopic polyangiitis. Journal of the American Society of Nephrology : JASN (2014) 25(5):990-7. Epub 2014/01/05. doi: 10.1681/asn.2013060606. PubMed PMID: 24385592; PubMed Central PMCID: PMCPMC4005303.

140. 140. Söderberg D, Segelmark M. Neutrophil Extracellular Traps in ANCA-Associated Vasculitis. Frontiers in immunology (2016) 7:256-. doi: 10.3389/fimmu.2016.00256. PubMed PMID: 27446086.

141. 141. Kraaij T, Bakker J, Brunini F, Pusey C, Scherer H, Toes R, et al. NET-inducing capacity is a biomarker in ANCAassociated vasculitis independent of ANCA antibodies. Arthritis \& Rheumatology (2016) 68((suppl 10)):1-15.

142. 142. Nakazawa D, Marschner JA, Platen L, Anders H-J. Extracellular traps in kidney disease. Kidney international (2018) 94(6):1087-98. doi: https://doi.org/10.1016/j.kint.2018.08.035.

143. 143. Chen K, Nishi H, Travers R, Tsuboi N, Martinod K, Wagner DD, et al. Endocytosis of soluble immune complexes leads to their clearance by Fc $\gamma$ RIIIB but induces neutrophil extracellular traps via Fc $\gamma$ RIIA in vivo. Blood (2012) 120(22):4421-31. doi: https://doi.org/10.1182/blood-2011-12-401133.

144. 144. Nishi H, Furuhashi K, Cullere X, Saggu G, Miller MJ, Chen Y, et al. Neutrophil Fc $\gamma$ RIIA promotes IgG-mediated glomerular neutrophil capture via Abl/Src kinases. The Journal of clinical investigation (2017) 127(10):3810-26. Epub 2017/09/12. doi: 10.1172/jci94039. PubMed PMID: 28891817; PubMed Central PMCID: PMCPMC5617671 patent, “Treatment of IgG-immune complex mediated organ damage" (serial nos. 61/990,873).

145. 145. Gordon RA, Herter JM, Rosetti F, Campbell AM, Nishi H, Kashgarian M, et al. Lupus and proliferative nephritis are PAD4 independent in murine models. JCI insight (2017) 2(10). Epub 2017/05/19. doi: 10.1172/jci.insight.92926. PubMed PMID: 28515361; PubMed Central PMCID: PMCPMC5436537.

146. 146. Okazaki T, Shinagawa S, Mikage H. Vasculitis syndrome-diagnosis and therapy. Journal of general and family medicine (2017) 18(2):72-8. Epub 2017/12/22. doi: 10.1002/jgf2.4. PubMed PMID: 29263994; PubMed Central PMCID: PMCPMC5689388.

147. 147. Yates M, Watts R. ANCA-associated vasculitis. Clinical medicine (London, England) (2017) 17(1):60-4. Epub 2017/02/06. doi: 10.7861/clinmedicine.17-1-60. PubMed PMID: 28148583; PubMed Central PMCID: PMCPMC6297586.

148. 148. Yoshida M, Sasaki M, Sugisaki K, Yamaguchi Y, Yamada M. Neutrophil extracellular trap components in fibrinoid necrosis of the kidney with myeloperoxidase-ANCA-associated vasculitis. Clin Kidney J (2013) 6(3):308-12. Epub 2013/06/01. doi: 10.1093/ckj/sft048. PubMed PMID: 26064491; PubMed Central PMCID: PMCPMC4400491.

149. 149. Nishide M, Nojima S, Ito D, Takamatsu H, Koyama S, Kang S, et al. Semaphorin 4D inhibits neutrophil activation and is involved in the pathogenesis of neutrophil-mediated autoimmune vasculitis. Annals of the rheumatic diseases (2017) 76(8):1440-8. Epub 2017/04/19. doi: 10.1136/annrheumdis-2016-210706. PubMed PMID: 28416516; PubMed Central PMCID: PMCPMC5738596.

150. 150. Sha LL, Wang H, Wang C, Peng HY, Chen M, Zhao MH. Autophagy is induced by anti-neutrophil cytoplasmic Abs and promotes neutrophil extracellular traps formation. Innate immunity (2016) 22(8):658-65. Epub 2016/09/28. doi: 10.1177/1753425916668981. PubMed PMID: 27670946.

151. 151. Ishida H, Ohkawa K, Hosui A, Hiramatsu N, Kanto T, Ueda K, et al. Involvement of p38 signaling pathway in interferon-alpha-mediated antiviral activity toward hepatitis $\mathrm{C}$ virus. Biochemical and biophysical research communications (2004) 321(3):722-7. Epub 2004/09/11. doi: 10.1016/j.bbrc.2004.07.015. PubMed PMID: 15358166.

152. 152. Ma YH, Ma TT, Wang C, Wang H, Chang DY, Chen M, et al. High-mobility group box 1 potentiates antineutrophil cytoplasmic antibody-inducing neutrophil extracellular traps formation. Arthritis research \& therapy (2016) 18:2. Epub 2016/01/08. doi: 10.1186/s13075-015-0903-z. PubMed PMID: 26739852; PubMed Central PMCID: PMCPMC4718033.

153. 153. Shida H, Nakazawa D, Tateyama Y, Miyoshi A, Kusunoki Y, Hattanda F, et al. The Presence of Anti-Lactoferrin Antibodies in a Subgroup of Eosinophilic Granulomatosis with Polyangiitis Patients and Their Possible Contribution to Enhancement of Neutrophil Extracellular Trap Formation. Frontiers in immunology (2016) 7:636. Epub 2017/01/10. doi: 10.3389/fimmu.2016.00636. PubMed PMID: 28066444; PubMed Central PMCID: PMCPMC5179553.

154. 154. Kettritz R, Jennette JC, Falk RJ. Crosslinking of ANCA-antigens stimulates superoxide release by human neutrophils. J Am Soc Nephrol (1997) 8(3):386-94. Epub 1997/03/01. PubMed PMID: 9071707.

155. 155. Shingu M, Nonaka S, Nishimukai H, Nobunaga M, Kitamura H, Tomo-Oka K. Activation of complement in normal serum by hydrogen peroxide and hydrogen peroxide-related oxygen radicals produced by activated neutrophils. Clinical and experimental immunology (1992) 90(1):72-8. doi: 10.1111/j.1365-2249.1992.tb05834.x. PubMed PMID: 1327592.

156. 156. Vogt W. Complement activation by myeloperoxidase products released from stimulated human polymorphonuclear leukocytes. Immunobiology (1996) 195(3):334-46. Epub 1996/08/01. doi: 10.1016/S0171-2985(96)80050-7. PubMed PMID: 8877407.

157. 157. Wirthmueller U, Dewald B, Thelen M, Schäfer MK, Stover C, Whaley K, et al. Properdin, a positive regulator of complement activation, is released from secondary granules of stimulated peripheral blood neutrophils. Journal of immunology (Baltimore, Md : 1950) (1997) 158(9):4444-51. Epub 1997/05/01. PubMed PMID: 9127010.

158. 158. Dick J, Gan PY, Ford SL, Odobasic D, Alikhan MA, Loosen SH, et al. C5a receptor 1 promotes autoimmunity, neutrophil dysfunction and injury in experimental anti-myeloperoxidase glomerulonephritis. Kidney Int (2018) 93(3):61525. Epub 2017/12/16. doi: 10.1016/j.kint.2017.09.018. PubMed PMID: 29241626. 
159. 159. Jayne DRW, Bruchfeld AN, Harper L, Schaier M, Venning MC, Hamilton P, et al. Randomized Trial of C5a Receptor Inhibitor Avacopan in ANCA-Associated Vasculitis. Journal of the American Society of Nephrology : JASN (2017) 28(9):2756-67. Epub 2017/04/13. doi: 10.1681/asn.2016111179. PubMed PMID: 28400446; PubMed Central PMCID: PMCPMC5576933.

160. 160. Lundberg K, Nijenhuis S, Vossenaar ER, Palmblad K, van Venrooij WJ, Klareskog L, et al. Citrullinated proteins have increased immunogenicity and arthritogenicity and their presence in arthritic joints correlates with disease severity. Arthritis research \& therapy (2005) 7(3):R458-67. Epub 2005/05/19. doi: 10.1186/ar1697. PubMed PMID: 15899032; PubMed Central PMCID: PMCPMC1174941.

161. 161. Clavel C, Nogueira L, Laurent L, Iobagiu C, Vincent C, Sebbag M, et al. Induction of macrophage secretion of tumor necrosis factor $\alpha$ through $\mathrm{F} c \gamma$ receptor IIa engagement by rheumatoid arthritis-specific autoantibodies to citrullinated proteins complexed with fibrinogen. Arthritis \& Rheumatism (2008) 58(3):678-88. doi: https://doi.org/10.1002/art.23284.

162. 162. Sokolove J, Zhao X, Chandra PE, Robinson WH. Immune complexes containing citrullinated fibrinogen costimulate macrophages via Toll-like receptor 4 and $F_{c} \gamma$ receptor. Arthritis and rheumatism (2011) 63(1):53-62. Epub 2010/10/19. doi: 10.1002/art.30081. PubMed PMID: 20954191; PubMed Central PMCID: PMCPMC3015008.

163. 163. Holers VM, Banda NK. Complement in the Initiation and Evolution of Rheumatoid Arthritis. Frontiers in immunology (2018) 9:1057-. doi: 10.3389/fimmu.2018.01057. PubMed PMID: 29892280.

164. 164. Sur Chowdhury C, Giaglis S, Walker UA, Buser A, Hahn S, Hasler P. Enhanced neutrophil extracellular trap generation in rheumatoid arthritis: analysis of underlying signal transduction pathways and potential diagnostic utility. Arthritis research \& therapy (2014) 16(3):R122. Epub 2014/06/15. doi: 10.1186/ar4579. PubMed PMID: 24928093; PubMed Central PMCID: PMCPMC4229860.

165. 165. Tanaka T, Narazaki M, Kishimoto T. IL-6 in inflammation, immunity, and disease. Cold Spring Harbor perspectives in biology (2014) 6(10):a016295-a. doi: 10.1101/cshperspect.a016295. PubMed PMID: 25190079.

166. 166 Endo H, Akahoshi T, Takagishi K, Kashiwazaki S, Matsushima K. Elevation of interleukin-8 (IL-8) levels in joint fluids of patients with rheumatoid arthritis and the induction by IL-8 of leukocyte infiltration and synovitis in rabbit joints. Lymphokine and cytokine research (1991) 10(4):245-52. Epub 1991/08/01. PubMed PMID: 1932367.

167. 167. Kaneko S, Satoh T, Chiba J, Ju C, Inoue K, Kagawa J. Interleukin-6 and interleukin-8 levels in serum and synovial fluid of patients with osteoarthritis. Cytokines, cellular \& molecular therapy (2000) 6(2):71-9. Epub 2000/12/07. doi: 10.1080/13684730050515796. PubMed PMID: 11108572.

168. 168. Farrugia M, Baron B. The role of TNF- $\alpha$ in rheumatoid arthritis: a focus on regulatory T cells. J Clin Transl Res (2016) 2(3):84-90. PubMed PMID: 30873466.

169. 169. Kumar P, Banik S. Pharmacotherapy options in rheumatoid arthritis. Clinical medicine insights Arthritis and musculoskeletal disorders (2013) 6:35-43. Epub 2013/09/03. doi: 10.4137/cmamd.S5558. PubMed PMID: 23997576; PubMed Central PMCID: PMCPMC3747998.

170. 170. Huang C, Wang Y, Li X, Ren L, Zhao J, Hu Y, et al. Clinical features of patients infected with 2019 novel coronavirus in Wuhan, China. The Lancet (2020) 395(10223):497-506. doi: 10.1016/S0140-6736(20)30183-5.

171. 171. Chen T, Wu D, Chen H, Yan W, Yang D, Chen G, et al. Clinical characteristics of 113 deceased patients with coronavirus disease 2019: retrospective study. BMJ (2020) 368:m1091. doi: 10.1136/bmj.m1091.

172. 172. Veras FP, Pontelli MC, Silva CM, Toller-Kawahisa JE, de Lima M, Nascimento DC, et al. SARS-CoV-2-triggered neutrophil extracellular traps mediate COVID-19 pathologySARS-CoV-2 directly triggers ACE-dependent NETs. Journal of Experimental Medicine (2020) 217(12). doi: 10.1084/jem.20201129.

173. 173. Zuo Y, Yalavarthi S, Shi H, Gockman K, Zuo M, Madison JA, et al. Neutrophil extracellular traps in COVID-19. JCI insight (2020) 5(11). doi: 10.1172/jci.insight.138999.

174. 174. Magro C, Mulvey JJ, Berlin D, Nuovo G, Salvatore S, Harp J, et al. Complement associated microvascular injury and thrombosis in the pathogenesis of severe COVID-19 infection: A report of five cases. Translational Research (2020) 220:1-13. doi: 10.1016/j.trsl.2020.04.007.

175. 175. Mehta P, McAuley DF, Brown M, Sanchez E, Tattersall RS, Manson JJ, et al. COVID-19: consider cytokine storm syndromes and immunosuppression. Lancet (London, England) (2020) 395(10229):1033-4. Epub 2020/03/16. doi: 10.1016/S0140-6736(20)30628-0. PubMed PMID: 32192578.

176. 176. Middleton EA, He X-Y, Denorme F, Campbell RA, Ng D, Salvatore SP, et al. Neutrophil extracellular traps contribute to immunothrombosis in COVID-19 acute respiratory distress syndrome. Blood (2020) 136(10):1169-79. doi: 10.1182/blood.2020007008.

177. 177. Skendros P, Mitsios A, Chrysanthopoulou A, Mastellos DC, Metallidis S, Rafailidis P, et al. Complement and tissue factor-enriched neutrophil extracellular traps are key drivers in COVID-19 immunothrombosis. The Journal of clinical investigation (2020) 130(11):6151-7. doi: 10.1172/JCI141374.

178. 178. Stakos D, Skendros P, Konstantinides S, Ritis K. Traps N' Clots: NET-Mediated Thrombosis and Related Diseases. Thrombosis and haemostasis (2020) 120(3):373-83. Epub 2020/01/16. doi: 10.1055/s-0039-3402731. PubMed PMID: 31940675.

179. 179. Stakos DA, Kambas K, Konstantinidis T, Mitroulis I, Apostolidou E, Arelaki S, et al. Expression of functional tissue factor by neutrophil extracellular traps in culprit artery of acute myocardial infarction. European heart journal (2015) 36(22):1405-14. Epub 2015/02/11. doi: 10.1093/eurheartj/ehv007. PubMed PMID: 25660055; PubMed Central PMCID: PMCPMC4458286. 
180. 180. Ritis K, Doumas M, Mastellos D, Micheli A, Giaglis S, Magotti P, et al. A novel C5a receptor-tissue factor crosstalk in neutrophils links innate immunity to coagulation pathways. Journal of immunology (Baltimore, Md : 1950) (2006) 177(7):4794-802. Epub 2006/09/20. doi: 10.4049/jimmunol.177.7.4794. PubMed PMID: 16982920.

181. 181. Redecha P, Tilley R, Tencati M, Salmon JE, Kirchhofer D, Mackman N, et al. Tissue factor: a link between C5a and neutrophil activation in antiphospholipid antibody induced fetal injury. Blood (2007) 110(7):2423-31. Epub 2007/05/31. doi: 10.1182/blood-2007-01-070631. PubMed PMID: 17536017; PubMed Central PMCID: PMCPMC1988945.

182. 182. Kourtzelis I, Markiewski MM, Doumas M, Rafail S, Kambas K, Mitroulis I, et al. Complement anaphylatoxin C5a contributes to hemodialysis-associated thrombosis. Blood (2010) 116(4):631-9. Epub 2010/04/29. doi: 10.1182/blood-2010-01264051. PubMed PMID: 20424189; PubMed Central PMCID: PMCPMC3086498.

183. 183. Chang SH, Park H, Dong C. Act1 Adaptor Protein Is an Immediate and Essential Signaling Component of Interleukin-17 Receptor *. Journal of Biological Chemistry (2006) 281(47):35603-7. doi: 10.1074/jbc.C600256200.

184. 184. Qian Y, Liu C, Hartupee J, Altuntas CZ, Gulen MF, Jane-wit D, et al. The adaptor Act1 is required for interleukin 17-dependent signaling associated with autoimmune and inflammatory disease. Nature Immunology (2007) 8(3):247-56. doi: $10.1038 /$ ni1439.

185. 185. Sønder SU, Saret S, Tang W, Sturdevant DE, Porcella SF, Siebenlist U. IL-17-induced NF-\&\#x3ba;B Activation via CIKS/Act1: PHYSIOLOGIC SIGNIFICANCE AND SIGNALING MECHANISMS * $<$ sup $></$ sup $>$. Journal of Biological Chemistry (2011) 286(15):12881-90. doi: 10.1074/jbc.M110.199547.

186. 186. Liu C, Qian W, Qian Y, Giltiay NV, Lu Y, Swaidani S, et al. Act1, a U-box E3 ubiquitin ligase for IL-17 signaling. Science signaling (2009) 2(92):ra63. Epub 2009/10/15. doi: 10.1126/scisignal.2000382. PubMed PMID: 19825828; PubMed Central PMCID: PMCPMC3182834.

187. 187. Luo Q, Sun Y, Liu W, Qian C, Jin B, Tao F, et al. A Novel Disease-Modifying Antirheumatic Drug, Iguratimod, Ameliorates Murine Arthritis by Blocking IL-17 Signaling, Distinct from Methotrexate and Leflunomide. The Journal of Immunology (2013) 191(10):4969-78. doi: 10.4049/jimmunol.1300832.

188. 188. Ellinghaus E, Ellinghaus D, Stuart PE, Nair RP, Debrus S, Raelson JV, et al. Genome-wide association study identifies a psoriasis susceptibility locus at TRAF3IP2. Nature genetics (2010) 42(11):991-5. doi: 10.1038/ng.689.

189. 189. Hüffmeier U, Uebe S, Ekici AB, Bowes J, Giardina E, Korendowych E, et al. Common variants at TRAF3IP2 are associated with susceptibility to psoriatic arthritis and psoriasis. Nature genetics (2010) 42(11):996-9. doi: 10.1038/ng.688.

190. 190. Strange A, Capon F, Spencer CCA, Knight J, Weale ME, Allen MH, et al. A genome-wide association study identifies new psoriasis susceptibility loci and an interaction between HLA-C and ERAP1. Nature genetics (2010) 42(11):985-90. doi: 10.1038/ng.694.

191. 191. Stuart Philip E, Nair Rajan P, Tsoi Lam C, Tejasvi T, Das S, Kang Hyun M, et al. Genome-wide Association Analysis of Psoriatic Arthritis and Cutaneous Psoriasis Reveals Differences in Their Genetic Architecture. The American Journal of Human Genetics (2015) 97(6):816-36. doi: 10.1016/j.ajhg.2015.10.019.

192. 192. Wang C, Wu L, Bulek K, Martin BN, Zepp JA, Kang Z, et al. The psoriasis-associated D10N variant of the adaptor Act1 with impaired regulation by the molecular chaperone hsp90. Nature immunology (2013) 14(1):72-81. Epub 2012/12/02. doi: 10.1038/ni.2479. PubMed PMID: 23202271.

193. 193. Hu SC, Yu HS, Yen FL, Lin CL, Chen GS, Lan CC. Neutrophil extracellular trap formation is increased in psoriasis and induces human $\beta$-defensin-2 production in epidermal keratinocytes. Scientific reports (2016) 6:31119. Epub 2016/08/06. doi: 10.1038/srep31119. PubMed PMID: 27493143; PubMed Central PMCID: PMCPMC4974609.

194. 194. Lin AM, Rubin CJ, Khandpur R, Wang JY, Riblett M, Yalavarthi S, et al. Mast cells and neutrophils release IL-17 through extracellular trap formation in psoriasis. J Immunol (2011) 187(1):490-500. Epub 2011/05/25. doi: 10.4049/jimmunol.1100123. PubMed PMID: 21606249; PubMed Central PMCID: PMCPMC3119764.

195. 195. Lambert S, Hambro CA, Johnston A, Stuart PE, Tsoi LC, Nair RP, et al. Neutrophil Extracellular Traps Induce Human Th17 Cells: Effect of Psoriasis-Associated TRAF3IP2 Genotype. The Journal of investigative dermatology (2019) 139(6):1245-53. Epub 2018/12/12. doi: 10.1016/j.jid.2018.11.021. PubMed PMID: 30528823; PubMed Central PMCID: PMCPMC7092801.

196. 196. Chen W, Chen H, Yang ZT, Mao EQ, Chen Y, Chen EZ. Free fatty acids-induced neutrophil extracellular traps lead to dendritic cells activation and T cell differentiation in acute lung injury. Aging (2021) 13(24):26148-60. Epub 2021/12/28. doi: 10.18632/aging.203802. PubMed PMID: 34959222; PubMed Central PMCID: PMCPMC8751615.

197. 197. Zhang H, Qiu SL, Tang QY, Zhou X, Zhang JQ, He ZY, et al. Erythromycin suppresses neutrophil extracellular traps in smoking-related chronic pulmonary inflammation. Cell death \& disease (2019) 10(9):678. Epub 2019/09/14. doi: 10.1038/s41419-019-1909-2. PubMed PMID: 31515489; PubMed Central PMCID: PMCPMC6742640.

198. 198. Krishnamoorthy N, Douda DN, Brüggemann TR, Ricklefs I, Duvall MG, Abdulnour RE, et al. Neutrophil cytoplasts induce $\mathrm{T}(\mathrm{H}) 17$ differentiation and skew inflammation toward neutrophilia in severe asthma. Science immunology (2018) 3(26). Epub 2018/08/05. doi: 10.1126/sciimmunol.aao4747. PubMed PMID: 30076281; PubMed Central PMCID: PMCPMC6320225.

199. 199. Faria DR, Gollob KJ, Barbosa J, Jr., Schriefer A, Machado PR, Lessa H, et al. Decreased in situ expression of interleukin-10 receptor is correlated with the exacerbated inflammatory and cytotoxic responses observed in mucosal leishmaniasis. Infect Immun (2005) 73(12):7853-9. Epub 2005/11/22. doi: 10.1128/iai.73.12.7853-7859.2005. PubMed PMID: 16299275; PubMed Central PMCID: PMCPMC1307048. 
200. 200. Faria DR, Souza PE, Durães FV, Carvalho EM, Gollob KJ, Machado PR, et al. Recruitment of CD8(+) T cells expressing granzyme A is associated with lesion progression in human cutaneous leishmaniasis. Parasite immunology (2009) 31(8):432-9. Epub 2009/08/04. doi: 10.1111/j.1365-3024.2009.01125.x. PubMed PMID: 19646207; PubMed Central PMCID: PMCPMC2764276.

201. 201. Cardoso TM, Machado Á, Costa DL, Carvalho LP, Queiroz A, Machado P, et al. Protective and pathological functions of CD8+ T cells in Leishmania braziliensis infection. Infect Immun (2015) 83(3):898-906. Epub 2014/12/24. doi: 10.1128/iai.02404-14. PubMed PMID: 25534940; PubMed Central PMCID: PMCPMC4333467.

202. 202. Guimarães-Costa AB, Nascimento MT, Froment GS, Soares RP, Morgado FN, Conceição-Silva F, et al. Leishmania amazonensis promastigotes induce and are killed by neutrophil extracellular traps. Proc Natl Acad Sci U S A (2009) 106(16):6748-53. Epub 2009/04/07. doi: 10.1073/pnas.0900226106. PubMed PMID: 19346483; PubMed Central PMCID: PMCPMC2672475.

203. 203. Morgado FN, Nascimento MT, Saraiva EM, de Oliveira-Ribeiro C, Madeira Mde F, da Costa-Santos M, et al. Are Neutrophil Extracellular Traps Playing a Role in the Parasite Control in Active American Tegumentary Leishmaniasis Lesions? PloS one (2015) 10(7):e0133063. Epub 2015/07/21. doi: 10.1371/journal.pone.0133063. PubMed PMID: 26192752; PubMed Central PMCID: PMCPMC4508047.

204. 204. Muniz VS, Weller PF, Neves JS. Eosinophil crystalloid granules: structure, function, and beyond. J Leukoc Biol (2012) 92(2):281-8. Epub 2012/06/08. doi: 10.1189/jlb.0212067. PubMed PMID: 22672875; PubMed Central PMCID: PMCPMC3395420.

205. 205. Yousefi S, Gold JA, Andina N, Lee JJ, Kelly AM, Kozlowski E, et al. Catapult-like release of mitochondrial DNA by eosinophils contributes to antibacterial defense. Nat Med (2008) 14(9):949-53. Epub 2008/08/12. doi: 10.1038/nm.1855. PubMed PMID: 18690244.

206. 206. Ueki S, Melo RC, Ghiran I, Spencer LA, Dvorak AM, Weller PF. Eosinophil extracellular DNA trap cell death mediates lytic release of free secretion-competent eosinophil granules in humans. Blood (2013) 121(11):2074-83. Epub 2013/01/11. doi: 10.1182/blood-2012-05-432088. PubMed PMID: 23303825; PubMed Central PMCID: PMCPMC3596967.

207. 207. Jacobs I, Ceulemans M, Wauters L, Breynaert C, Vermeire S, Verstockt B, et al. Role of Eosinophils in Intestinal Inflammation and Fibrosis in Inflammatory Bowel Disease: An Overlooked Villain? Front Immunol (2021) 12:754413. Epub 2021/11/06. doi: 10.3389/fimmu.2021.754413. PubMed PMID: 34737752; PubMed Central PMCID: PMCPMC8560962.

208. 208. Choi Y, Le Pham D, Lee DH, Lee SH, Kim SH, Park HS. Biological function of eosinophil extracellular traps in patients with severe eosinophilic asthma. Exp Mol Med (2018) 50(8):1-8. Epub 2018/08/18. doi: 10.1038/s12276-018-0136-8. PubMed PMID: 30115903; PubMed Central PMCID: PMCPMC6095846.

209. 209. da Cunha AA, Nunez NK, de Souza RG, Moraes Vargas MH, Silveira JS, Antunes GL, et al. Recombinant human deoxyribonuclease therapy improves airway resistance and reduces DNA extracellular traps in a murine acute asthma model. Exp Lung Res (2016) 42(2):66-74. Epub 2016/04/14. doi: 10.3109/01902148.2016.1143537. PubMed PMID: 27070484.

210. 210. Shak S, Capon DJ, Hellmiss R, Marsters SA, Baker CL. Recombinant human DNase I reduces the viscosity of cystic fibrosis sputum. Proc Natl Acad Sci U S A (1990) 87(23):9188-92. Epub 1990/12/01. doi: 10.1073/pnas.87.23.9188. PubMed PMID: 2251263; PubMed Central PMCID: PMCPMC55129.

211. 211. Ueki S, Konno Y, Takeda M, Moritoki Y, Hirokawa M, Matsuwaki Y, et al. Eosinophil extracellular trap cell deathderived DNA traps: Their presence in secretions and functional attributes. J Allergy Clin Immunol (2016) 137(1):258-67. Epub 2015/06/14. doi: 10.1016/j.jaci.2015.04.041. PubMed PMID: 26070883; PubMed Central PMCID: PMCPMC4674385.

212. 212. Hwang CS, Park SC, Cho HJ, Park DJ, Yoon JH, Kim CH. Eosinophil extracellular trap formation is closely associated with disease severity in chronic rhinosinusitis regardless of nasal polyp status. Sci Rep (2019) 9(1):8061. Epub 2019/05/31. doi: 10.1038/s41598-019-44627-z. PubMed PMID: 31147604; PubMed Central PMCID: PMCPMC6542829.

213. 213. Gevaert E, Zhang N, Krysko O, Lan F, Holtappels G, De Ruyck N, et al. Extracellular eosinophilic traps in association with Staphylococcus aureus at the site of epithelial barrier defects in patients with severe airway inflammation. J Allergy Clin Immunol (2017) 139(6):1849-60 e6. Epub 2017/02/22. doi: 10.1016/j.jaci.2017.01.019. PubMed PMID: 28216437.

214. 214. Ohta N, Ueki S, Konno Y, Hirokawa M, Kubota T, Tomioka-Matsutani S, et al. ETosis-derived DNA trap production in middle ear effusion is a common feature of eosinophilic otitis media. Allergol Int (2018) 67(3):414-6. Epub 2017/12/16. doi: 10.1016/j.alit.2017.11.007. PubMed PMID: 29242145.

215. 215. Hashimoto T, Ueki S, Kamide Y, Miyabe Y, Fukuchi M, Yokoyama Y, et al. Increased Circulating Cell-Free DNA in Eosinophilic Granulomatosis With Polyangiitis: Implications for Eosinophil Extracellular Traps and Immunothrombosis. Front Immunol (2021) 12:801897. Epub 2022/02/01. doi: 10.3389/fimmu.2021.801897. PubMed PMID: 35095884; PubMed Central PMCID: PMCPMC8790570.

216. 216. Beaven MA. Our perception of the mast cell from Paul Ehrlich to now. Eur J Immunol (2009) 39(1):11-25. Epub 2009/01/09. doi: 10.1002/eji.200838899. PubMed PMID: 19130582; PubMed Central PMCID: PMCPMC2950100.

217. 217. Dwyer DF, Barrett NA, Austen KF, Immunological Genome Project C. Expression profiling of constitutive mast cells reveals a unique identity within the immune system. Nat Immunol (2016) 17(7):878-87. Epub 2016/05/03. doi: 10.1038/ni.3445. PubMed PMID: 27135604; PubMed Central PMCID: PMCPMC5045264.

218. 218. Pejler G, Abrink M, Ringvall M, Wernersson S. Mast cell proteases. Adv Immunol (2007) 95:167-255. Epub 2007/09/18. doi: 10.1016/S0065-2776(07)95006-3. PubMed PMID: 17869614.

219. 219. Wernersson S, Pejler G. Mast cell secretory granules: armed for battle. Nat Rev Immunol (2014) 14(7):478-94. Epub 2014/06/07. doi: 10.1038/nri3690. PubMed PMID: 24903914. 
220. 220. Kraft S, Kinet JP. New developments in FcepsilonRI regulation, function and inhibition. Nat Rev Immunol (2007) 7(5):365-78. Epub 2007/04/18. doi: 10.1038/nri2072. PubMed PMID: 17438574.

221. 221. Galli SJ, Tsai M. IgE and mast cells in allergic disease. Nat Med (2012) 18(5):693-704. Epub 2012/05/09. doi: 10.1038/nm.2755. PubMed PMID: 22561833; PubMed Central PMCID: PMCPMC3597223.

222. 222. Supajatura V, Ushio H, Nakao A, Akira S, Okumura K, Ra C, et al. Differential responses of mast cell Toll-like receptors 2 and 4 in allergy and innate immunity. J Clin Invest (2002) 109(10):1351-9. Epub 2002/05/22. doi: 10.1172/JCI14704. PubMed PMID: 12021251; PubMed Central PMCID: PMCPMC150977.

223. 223. Gaudenzio N, Laurent C, Valitutti S, Espinosa E. Human mast cells drive memory CD4+ T cells toward an inflammatory IL-22+ phenotype. J Allergy Clin Immunol (2013) 131(5):1400-7 e11. Epub 2013/03/23. doi: 10.1016/j.jaci.2013.01.029. PubMed PMID: 23518141.

224. 224. Nija RJ, Sanju S, Sidharthan N, Mony U. Extracellular Trap by Blood Cells: Clinical Implications. Tissue Eng Regen Med (2020) 17(2):141-53. Epub 2020/03/03. doi: 10.1007/s13770-020-00241-z. PubMed PMID: 32114678; PubMed Central PMCID: PMCPMC7105514.

225. 225. von Kockritz-Blickwede M, Goldmann O, Thulin P, Heinemann K, Norrby-Teglund A, Rohde M, et al. Phagocytosis-independent antimicrobial activity of mast cells by means of extracellular trap formation. Blood (2008) 111(6):3070-80. Epub 2008/01/10. doi: 10.1182/blood-2007-07-104018. PubMed PMID: 18182576.

226. 226. Cregar L, Elrod KC, Putnam D, Moore WR. Neutrophil myeloperoxidase is a potent and selective inhibitor of mast cell tryptase. Arch Biochem Biophys (1999) 366(1):125-30. Epub 1999/05/21. doi: 10.1006/abbi.1999.1220. PubMed PMID: 10334872.

227. 227. Lowy FD. Staphylococcus aureus infections. N Engl J Med (1998) 339(8):520-32. Epub 1998/08/26. doi: 10.1056/NEJM199808203390806. PubMed PMID: 9709046.

228. 228. Garcia-Rodriguez KM, Bahri R, Sattentau C, Roberts IS, Goenka A, Bulfone-Paus S. Human mast cells exhibit an individualized pattern of antimicrobial responses. Immun Inflamm Dis (2020) 8(2):198-210. Epub 2020/03/30. doi: 10.1002/iid3.295. PubMed PMID: 32222064; PubMed Central PMCID: PMCPMC7212193.

229. 229. Lauth X, von Kockritz-Blickwede M, McNamara CW, Myskowski S, Zinkernagel AS, Beall B, et al. M1 protein allows Group A streptococcal survival in phagocyte extracellular traps through cathelicidin inhibition. J Innate Immun (2009) 1(3):202-14. Epub 2009/01/01. doi: 10.1159/000203645. PubMed PMID: 20375578; PubMed Central PMCID: PMCPMC3241932.

230. 230. Lopes JP, Stylianou M, Nilsson G, Urban CF. Opportunistic pathogen Candida albicans elicits a temporal response in primary human mast cells. Sci Rep (2015) 5:12287. Epub 2015/07/21. doi: 10.1038/srep12287. PubMed PMID: 26192381; PubMed Central PMCID: PMCPMC4507480.

231. 231. Pertiwi KR, de Boer OJ, Mackaaij C, Pabittei DR, de Winter RJ, Li X, et al. Extracellular traps derived from macrophages, mast cells, eosinophils and neutrophils are generated in a time-dependent manner during atherothrombosis. J Pathol (2019) 247(4):505-12. Epub 2018/12/07. doi: 10.1002/path.5212. PubMed PMID: 30506885; PubMed Central PMCID: PMCPMC6590313.

232. 232. Morshed M, Hlushchuk R, Simon D, Walls AF, Obata-Ninomiya K, Karasuyama H, et al. NADPH oxidase-independent formation of extracellular DNA traps by basophils. J Immunol (2014) 192(11):5314-23. Epub 2014/04/29. doi: 10.4049/jimmunol.1303418. PubMed PMID: 24771850.

233. 233. King PT, Sharma R, O'Sullivan K, Selemidis S, Lim S, Radhakrishna N, et al. Nontypeable Haemophilus influenzae induces sustained lung oxidative stress and protease expression. PLoS One (2015) 10(3):e0120371. Epub 2015/03/21. doi: 10.1371/journal.pone.0120371. PubMed PMID: 25793977; PubMed Central PMCID: PMCPMC4368769.

234. 234. King PT, Sharma R, O'Sullivan KM, Callaghan J, Dousha L, Thomas B, et al. Deoxyribonuclease 1 reduces pathogenic effects of cigarette smoke exposure in the lung. Sci Rep (2017) 7(1):12128. Epub 2017/09/25. doi: 10.1038/s41598-01712474-5. PubMed PMID: 28935869; PubMed Central PMCID: PMCPMC5608940.

235. 235. King PT, Dousha L, Clarke N, Schaefer J, Carzino R, Sharma R, et al. Phagocyte extracellular traps in children with neutrophilic airway inflammation. ERJ Open Res (2021) 7(2). Epub 2021/06/25. doi: 10.1183/23120541.00883-2020. PubMed PMID: 34164555; PubMed Central PMCID: PMCPMC8215332 Dousha has nothing to disclose. Conflict of interest: N. Clarke has nothing to disclose. Conflict of interest: J. Schaefer has nothing to disclose. Conflict of interest: R. Carzino has nothing to disclose. Conflict of interest: R. Sharma has nothing to disclose. Conflict of interest: K.L. Wan has nothing to disclose. Conflict of interest: A. Ananthrajah has nothing to disclose. Conflict of interest: K. O'Sullivan has nothing to disclose. Conflict of interest: Z.X. Lu has nothing to disclose. Conflict of interest: S.R. Holdsworth has nothing to disclose. Conflict of interest: S. Ranganathan has nothing to disclose. Conflict of interest: P.G. Bardin has nothing to disclose. Conflict of interest: D.S. Armstrong has nothing to disclose.

236. 236. Liu P, Wu X, Liao C, Liu X, Du J, Shi H, et al. Escherichia coli and Candida albicans induced macrophage extracellular trap-like structures with limited microbicidal activity. PLoS One (2014) 9(2):e90042. Epub 2014/03/04. doi: 10.1371/journal.pone.0090042. PubMed PMID: 24587206; PubMed Central PMCID: PMCPMC3934966.

237. 237. Chow OA, von Kockritz-Blickwede M, Bright AT, Hensler ME, Zinkernagel AS, Cogen AL, et al. Statins enhance formation of phagocyte extracellular traps. Cell Host Microbe (2010) 8(5):445-54. Epub 2010/11/16. doi: 10.1016/j.chom.2010.10.005. PubMed PMID: 21075355; PubMed Central PMCID: PMCPMC3008410.

238. 238. Loures FV, Rohm M, Lee CK, Santos E, Wang JP, Specht CA, et al. Recognition of Aspergillus fumigatus hyphae by human plasmacytoid dendritic cells is mediated by dectin-2 and results in formation of extracellular traps. PLoS Pathog 
(2015) 11(2):e1004643. Epub 2015/02/07. doi: 10.1371/journal.ppat.1004643. PubMed PMID: 25659141; PubMed Central PMCID: PMCPMC4450068.

239. 239. Branzk N, Lubojemska A, Hardison SE, Wang Q, Gutierrez MG, Brown GD, et al. Neutrophils sense microbe size and selectively release neutrophil extracellular traps in response to large pathogens. Nat Immunol (2014) 15(11):1017-25. Epub 2014/09/15. doi: 10.1038/ni.2987. PubMed PMID: 25217981; PubMed Central PMCID: PMCPMC4236687.

240. 240. Chamardani TM, Amiritavassoli S. Inhibition of NETosis for treatment purposes: friend or foe? Mol Cell Biochem (2022) 477(3):673-88. Epub 2022/01/08. doi: 10.1007/s11010-021-04315-x. PubMed PMID: 34993747; PubMed Central PMCID: PMCPMC8736330.

241. 241. O'Sullivan KM, Holdsworth SR. Neutrophil Extracellular Traps: A Potential Therapeutic Target in MPO-ANCA Associated Vasculitis? Front Immunol (2021) 12:635188. Epub 2021/04/02. doi: 10.3389/fimmu.2021.635188. PubMed PMID: 33790907; PubMed Central PMCID: PMCPMC8005609.

242. 242. Davis JC, Jr., Manzi S, Yarboro C, Rairie J, McInnes I, Averthelyi D, et al. Recombinant human Dnase I (rhDNase) in patients with lupus nephritis. Lupus (1999) 8(1):68-76. Epub 1999/02/20. doi: 10.1191/096120399678847380. PubMed PMID: 10025601.

243. 243. Shiokawa D, Tanuma S. Characterization of human DNase I family endonucleases and activation of DNase gamma during apoptosis. Biochemistry (2001) 40(1):143-52. Epub 2001/01/05. doi: 10.1021/bi001041a. PubMed PMID: 11141064.

244. 244. Jimenez-Alcazar M, Rangaswamy C, Panda R, Bitterling J, Simsek YJ, Long AT, et al. Host DNases prevent vascular occlusion by neutrophil extracellular traps. Science (2017) 358(6367):1202-6. Epub 2017/12/02. doi: 10.1126/science.aam8897. PubMed PMID: 29191910.

245. 245. Rohrbach AS, Slade DJ, Thompson PR, Mowen KA. Activation of PAD4 in NET formation. Front Immunol (2012) 3:360. Epub 2012/12/25. doi: 10.3389/fimmu.2012.00360. PubMed PMID: 23264775; PubMed Central PMCID: PMCPMC3525017.

246. 246. Knight JS, Subramanian V, O'Dell AA, Yalavarthi S, Zhao W, Smith CK, et al. Peptidylarginine deiminase inhibition disrupts NET formation and protects against kidney, skin and vascular disease in lupus-prone MRL/lpr mice. Ann Rheum Dis (2015) 74(12):2199-206. Epub 2014/08/12. doi: 10.1136/annrheumdis-2014-205365. PubMed PMID: 25104775; PubMed Central PMCID: PMCPMC4320672.

247. 247. Knight JS, Zhao W, Luo W, Subramanian V, O'Dell AA, Yalavarthi S, et al. Peptidylarginine deiminase inhibition is immunomodulatory and vasculoprotective in murine lupus. J Clin Invest (2013) 123(7):2981-93. Epub 2013/06/01. doi: 10.1172/JCI67390. PubMed PMID: 23722903; PubMed Central PMCID: PMCPMC3696545.

248. 248. Biron BM, Chung CS, O'Brien XM, Chen Y, Reichner JS, Ayala A. Cl-Amidine Prevents Histone 3 Citrullination and Neutrophil Extracellular Trap Formation, and Improves Survival in a Murine Sepsis Model. J Innate Immun (2017) 9(1):22-32. Epub 2016/09/14. doi: 10.1159/000448808. PubMed PMID: 27622642; PubMed Central PMCID: PMCPMC5219946.

249. 249. Knight JS, Luo W, O'Dell AA, Yalavarthi S, Zhao W, Subramanian V, et al. Peptidylarginine deiminase inhibition reduces vascular damage and modulates innate immune responses in murine models of atherosclerosis. Circ Res (2014) 114(6):947-56. Epub 2014/01/16. doi: 10.1161/CIRCRESAHA.114.303312. PubMed PMID: 24425713; PubMed Central PMCID: PMCPMC4185401.

250. 250. Curran AM, Naik P, Giles JT, Darrah E. PAD enzymes in rheumatoid arthritis: pathogenic effectors and autoimmune targets. Nat Rev Rheumatol (2020) 16(6):301-15. Epub 2020/04/29. doi: 10.1038/s41584-020-0409-1. PubMed PMID: 32341463.

251. 251. Li P, Li M, Lindberg MR, Kennett MJ, Xiong N, Wang Y. PAD4 is essential for antibacterial innate immunity mediated by neutrophil extracellular traps. J Exp Med (2010) 207(9):1853-62. Epub 2010/08/25. doi: 10.1084/jem.20100239. PubMed PMID: 20733033; PubMed Central PMCID: PMCPMC2931169.

252. 252. Elborn JS, Perrett J, Forsman-Semb K, Marks-Konczalik J, Gunawardena K, Entwistle N. Efficacy, safety and effect on biomarkers of AZD9668 in cystic fibrosis. Eur Respir J (2012) 40(4):969-76. Epub 2012/01/24. doi: 10.1183/09031936.00194611. PubMed PMID: 22267768.

253. 253. Kuna P, Jenkins M, O'Brien CD, Fahy WA. AZD9668, a neutrophil elastase inhibitor, plus ongoing budesonide/formoterol in patients with COPD. Respir Med (2012) 106(4):531-9. Epub 2011/12/27. doi: 10.1016/j.rmed.2011.10.020. PubMed PMID: 22197578.

254. 254. Stockley R, De Soyza A, Gunawardena K, Perrett J, Forsman-Semb K, Entwistle N, et al. Phase II study of a neutrophil elastase inhibitor (AZD9668) in patients with bronchiectasis. Respir Med (2013) 107(4):524-33. Epub 2013/02/26. doi: 10.1016/j.rmed.2012.12.009. PubMed PMID: 23433769.

255. 255. Li H, Zhou X, Tan H, Hu Y, Zhang L, Liu S, et al. Neutrophil extracellular traps contribute to the pathogenesis of acid-aspiration-induced ALI/ARDS. Oncotarget (2018) 9(2):1772-84. Epub 2018/02/09. doi: 10.18632/oncotarget.22744. PubMed PMID: 29416730; PubMed Central PMCID: PMCPMC5788598.

256. 256. Hu JJ, Liu X, Xia S, Zhang Z, Zhang Y, Zhao J, et al. FDA-approved disulfiram inhibits pyroptosis by blocking gasdermin D pore formation. Nat Immunol (2020) 21(7):736-45. Epub 2020/05/06. doi: 10.1038/s41590-020-0669-6. PubMed PMID: 32367036; PubMed Central PMCID: PMCPMC7316630.

257. 257. Adrover JM, Carrau L, Dassler-Plenker J, Bram Y, Chandar V, Houghton S, et al. Disulfiram inhibits neutrophil extracellular trap formation protecting rodents from acute lung injury and SARS-CoV-2 infection. JCI Insight (2022). Epub 2022/02/09. doi: 10.1172/jci.insight.157342. PubMed PMID: 35133984. 
258. 258. Urban CF, Reichard U, Brinkmann V, Zychlinsky A. Neutrophil extracellular traps capture and kill Candida albicans yeast and hyphal forms. Cellular Microbiology (2006) 8(4):668-76. doi: https://doi.org/10.1111/j.14625822.2005.00659.x.

259. 259. Keshari RS, Jyoti A, Dubey M, Kothari N, Kohli M, Bogra J, et al. Cytokines induced neutrophil extracellular traps formation: implication for the inflammatory disease condition. PloS one (2012) 7(10):e48111-e. Epub 2012/10/26. doi: 10.1371/journal.pone.0048111. PubMed PMID: 23110185.

260. 260. Garcia-Romo GS, Caielli S, Vega B, Connolly J, Allantaz F, Xu Z, et al. Netting neutrophils are major inducers of type I IFN production in pediatric systemic lupus erythematosus. Science translational medicine (2011) 3(73):73ra20-73ra20. doi: 10.1126/scitranslmed.3001201. PubMed PMID: 21389264.

261. 261. Kessenbrock K, Krumbholz M, Schonermarck U, Back W, Gross WL, Werb Z, et al. Netting neutrophils in autoimmune small-vessel vasculitis. Nat Med (2009) 15(6):623-5. Epub 2009/05/19. doi: 10.1038/nm.1959. PubMed PMID: 19448636; PubMed Central PMCID: PMCPMC2760083.

262. 262. O'Donoghue AJ, Jin Y, Knudsen GM, Perera NC, Jenne DE, Murphy JE, et al. Global substrate profiling of proteases in human neutrophil extracellular traps reveals consensus motif predominantly contributed by elastase. PloS one (2013) 8(9):e75141. Epub 2013/09/28. doi: 10.1371/journal.pone.0075141. PubMed PMID: 24073241; PubMed Central PMCID: PMCPMC3779220 Bayer HealthCare. This does not alter our adherence to all the PLOS ONE policies on sharing data and materials, as detailed online in the guide for authors.

263. 263. Wilson AS, Randall KL, Pettitt JA, Ellyard JI, Blumenthal A, Enders A, et al. Neutrophil extracellular traps and their histones promote Th17 cell differentiation directly via TLR2. Nature communications (2022) 13(1):528. doi: 10.1038/s41467-022-28172-4.

264. 264. Foley JF. STAT3 Regulates the Generation of Th17 Cells. Science's STKE (2007) 2007(380):tw113-tw. doi: doi:10.1126/stke.3802007tw113.

265. 265. Komiyama Y, Nakae S, Matsuki T, Nambu A, Ishigame H, Kakuta S, et al. IL-17 Plays an Important Role in the Development of Experimental Autoimmune Encephalomyelitis. The Journal of Immunology (2006) 177(1):566-73. doi: 10.4049 